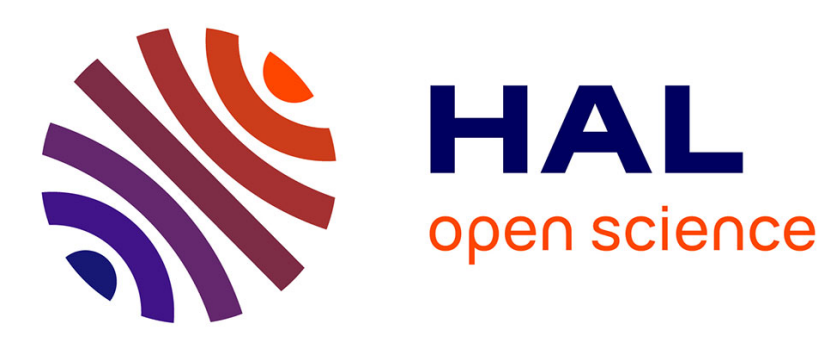

\title{
Joint optimisation of operation and maintenance policies in an urban ropeway transport systems context
}

\author{
Ronald Martinod, Olivier Bistorin, Leonel F Castaneda, Nidhal Rezg
}

\section{To cite this version:}

Ronald Martinod, Olivier Bistorin, Leonel F Castaneda, Nidhal Rezg. Joint optimisation of operation and maintenance policies in an urban ropeway transport systems context. International Journal of Quality and Reliability Management, 2019, 36 (7), pp.1106-1136. 10.1108/IJQRM-10-2018-0292 . hal-02144551v2

\author{
HAL Id: hal-02144551 \\ https://hal.science/hal-02144551v2
}

Submitted on 30 Sep 2019

HAL is a multi-disciplinary open access archive for the deposit and dissemination of scientific research documents, whether they are published or not. The documents may come from teaching and research institutions in France or abroad, or from public or private research centers.
L'archive ouverte pluridisciplinaire HAL, est destinée au dépôt et à la diffusion de documents scientifiques de niveau recherche, publiés ou non, émanant des établissements d'enseignement et de recherche français ou étrangers, des laboratoires publics ou privés. 
archives-ouvertes

\title{
Joint optimisation of operation and maintenance policies in an urban ropeway transport systems context
}

\author{
Leonel Castañeda, Ronald Martinod, R.M. Martinod, Olivier Bistorin, Leonel
} Castaneda, Nidhal Rezg

\section{- To cite this version:}

Leonel Castañeda, Ronald Martinod, R.M. Martinod, Olivier Bistorin, Leonel Castaneda, et al.. Joint optimisation of operation and maintenance policies in an urban ropeway transport systems context. International Journal of Quality and Reliability Management, Emerald, 2019, 36 (7), pp.1106-1136. 10.1108/IJQRM-10-2018-0292 . hal-02144551v2

\section{HAL Id: hal-02144551 \\ https://hal.archives-ouvertes.fr/hal-02144551v2}

Submitted on 30 Sep 2019

HAL is a multi-disciplinary open access archive for the deposit and dissemination of scientific research documents, whether they are published or not. The documents may come from teaching and research institutions in France or abroad, or from public or private research centers.
L'archive ouverte pluridisciplinaire HAL, est destinée au dépôt et à la diffusion de documents scientifiques de niveau recherche, publiés ou non, émanant des établissements d'enseignement et de recherche français ou étrangers, des laboratoires publics ou privés. 


\section{QUERY FORM}

JOURNAL:

International Journal of Quality \& Reliability Management

VOL/ISSUE NO: $\quad 00 / 00$

ARTICLE NO: $\quad \mathbf{6 2 3 9 5 4}$

ARTICLE TITLE: Joint optimisation of operation and maintenance policies in an urban ropeway transport systems context

AUTHORS:

Ronald Matrieio_Martinod, Olivier Bistorin, Leonel Castañeda and Nidhal Rezg

Note to Editors:

The queries listed in the table below are for the Author. Please ignore these queries.

Note to Authors: $\quad$ During the production of your article we came across the following queries listed in the table below. Please review the queries and insert your reply or correction at the corresponding line in the PDF proof of the article which follows this query page.

\begin{tabular}{|c|c|}
\hline No. & Queries \\
\hline Q1 & $\begin{array}{l}\text { References Moubray (2003), Prestonand Raje (2007) and Khatab (2013) are cited in the text but not } \\
\text { included in the reference list. Please provide complete publication details to include in the reference } \\
\text { list; else confirm the deletion of the text citation. }\end{array}$ \\
\hline Q2 & $\begin{array}{l}\text { Two references share the same author name "Hajej et al." and year "2014". They are differentiated as } \\
\text { "Hajej, Dellagi and Rezg (2014)" and "Hajej, Turki and Rezg (2014)" in the reference list. Please specify } \\
\text { whether it is "Hajej, Dellagi and Rezg (2014)" or "Hajej, Turki and Rezg (2014)" in the sentence "Later, } \\
\text { Hajej, Dellagi and Rezg (2014) and Hajej, Turki and Rezg (2014) dealt with the problem of jointly } \\
\text { optimising maintenance..." Please check elsewhere for the same in the text. }\end{array}$ \\
\hline Q3 & $\begin{array}{l}\text { Alshalalfah (2014) has been changed to Alshalalfah et al. (2014) so that this citation matches the } \\
\text { reference list in the sentence "Urban ropeway ... infeasible to implement". Please confirm whether this } \\
\text { is correct. If not, please provide complete publication details for Alshalalfah (2014). }\end{array}$ \\
\hline Q4 & We have changed Table I to Nomenclature and renumbered all the tables. Please check. \\
\hline Q5 & $\begin{array}{l}\text { Kfahraman et al. (2011) has been changed to Kahraman and Gosavi (2011) so that this citation } \\
\text { matches the reference list in the sentence "If the number ... transportation mode". Please confirm } \\
\text { whether this is correct. If not, please provide complete publication details for Kfahraman et al. (2011). }\end{array}$ \\
\hline Q6 & Figures are provide without numbers. Please check whether they are numbered correctly. \\
\hline
\end{tabular}




\section{QUERY FORM}

JOURNAL:

International Journal of Quality \& Reliability Management

VOL/ISSUE NO: $\quad 00 / 00$

ARTICLE NO: $\quad \mathbf{6 2 3 9 5 4}$

ARTICLE TITLE: Joint optimisation of operation and maintenance policies in an urban ropeway transport systems context

AUTHORS:

Ronald Matrieio_Martinod, Olivier Bistorin, Leonel Castañeda and Nidhal Rezg

Note to Editors: $\quad$ The queries listed in the table below are for the Author. Please ignore these queries.

Note to Authors: $\quad$ During the production of your article we came across the following queries listed in the table below. Please review the queries and insert your reply or correction at the corresponding line in the PDF proof of the article which follows this query page.

\begin{tabular}{|c|l|}
\hline Q7 & $\begin{array}{l}\text { Please provide issue number in references: Alshalalfah } \text { et al. (2012), Amirgholy and Gonzales (2016), } \\
\text { Barrena } \text { et al. (2014a), Barrena } \text { et al. (2014b), Bocarejo } \text { et al. (2014), Ceder } \text { et al. (2013), Gillen and } \\
\text { Hasheminia (2013), Hajej } \text { et al. (2014), Heinrichs and Bernet (2014), Ibarra-Rojas } \text { et al. (2015), Ison and } \\
\text { Sagaris (2016), Jenelius (2018), Jones } \text { et al. (2000), Li and Sheng (2016), Martinod } \text { et al. (2018), Martinod } \\
\text { et al. (2015), Nesheli } \text { et al. (2015), Niu and Zhou (2013), Parbo et al. (2014), Pham and Wang (1996), } \\
\text { Pitsiava-Latinopoulou and Iordanopoulos (2012), Reichenbach and Puhe (2018), Shang } \text { et al. (2016), } \\
\text { Sun } \text { et al. (2014), Sun } \text { et al. (2017), Wang } \text { et al. (2015), Wang } \text { et al. (2014), Wu and Mengersen (2014), Yin } \\
\text { et al. (2017). }\end{array}$ \\
\hline Q8 & $\begin{array}{l}\text { Please provide the city location in references: Ceder (2007), Dalla-Chiara (2010), Spillar (1997), Taha } \\
\text { (2011), Trujillo (2013). }\end{array}$ \\
\hline Q9 & Please provide volume number and issue number in reference: Directive 2000/9/EC (2000). \\
\hline Q10 & Please provide the date in reference: Hajej et al. (2014). \\
\hline Q11 & Please provide the name of editor(s) and the city location in references: Hall (2003), Newell (1977). \\
\hline
\end{tabular}




\title{
RELIABILITY PAPER Joint optimisation of operation and maintenance policies in an urban ropeway transport systems context
}

\begin{abstract}
Purpose - The purpose of this paper is to propose a stochastic optimisation model for integrating service and maintenance policies in order to solve the queuing problem and the cost of maintenance activities for public transport services, with a particular focus on urban ropeway system.

Design/methodology/approach - The authors adopt the following approaches: a discrete-event model that uses a set of interrelated queues for the formulation of the service problem using a cost-based expression; and a maintenance model consisting of preventive and corrective maintenance actions, which considers two different maintenance policies (periodic block-type and age-based).

Findings - The work shows that neither periodic block-type maintenance nor an age-based maintenance is necessarily the best maintenance strategy over a long system lifecycle; the optimal strategy must consider both policies.

Practical implications - The maintenance policies are then evaluated for their impact on the service and operation of the transport system. The authors conclude by applying the proposed optimisation model using an example concerning ropeway systems.

Originality/value - This is the first study to simultaneously consider maintenance policy and operational policy in an urban aerial ropeway system, taking up the problem of queuing with particular attention to the unique requirements public transport services.
\end{abstract}

Keywords Public transport, Imperfect maintenance, Maintenance policy, Queuing theory,

Ropeway system, Urban passenger transport

Paper type Research paper

$$
\begin{aligned}
& \begin{array}{l}
\text { Nomenclature } \\
i=\{1,2, \ldots, I\}
\end{array} \\
& j=\{1,2, \ldots, J\} \\
& k=\{1,2, \ldots, K\}
\end{aligned}
$$

indices of the platforms on the ropeway systems indices of the components on the ropeway systems indices of the vehicles (gondolas) on the ropeway systems $m=\{1,2, \ldots\}$

$n=\{1,2, \ldots, N\}$

$a, b$

N indices of the user demand conditions from rush hour to valley hour indices of discretised time instants of time typical (representative) period of working time

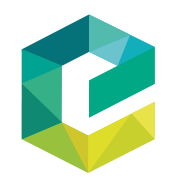


horizon of time, long time $W g_{s u p}$ window of working-life discretised time

$\Delta t$

Operational parameters:

cv

$f v_{n}$

$g_{k, i, n}$

$h_{i}$

$l_{n} \quad$ distance between vehicles over the $n$th discretised time (m)

Service policy parameters:

$F s_{i, n}$

$P a_{i, n}$

$l_{i}$

$\lambda_{i, n}$

$\mu_{i, n}$

$\sigma_{k, n}$

$L q_{i, n}$ function of effected

services at the $i$ th

platform over the $n$th

discretised time

probability function of

passengers arrival at the

$i$ th platform over the $n$th

discretised time

$p$

proportional coefficient of

$\lambda_{i, n}$ at the $i$ th platform

weighted mean of users

arrival at the $i$ th platform $f_{j}, F_{j}$

over the $n$th discretised

time $(\operatorname{pax} / \Delta t)$

passengers boarding $\quad r_{j, n}$

average from the $i$ th

platform over the $n$th

discretised time $(\mathrm{pax} / \Delta t)$

effected services average $\omega_{j}$

(disembarking passengers

from the $k$ th vehicle) over $R_{j}, R g$

the $n$th discretised time

$(\operatorname{pax} / \Delta t)$

quantity of users in the

queue at the $i$ th platform $R g_{\text {inf }}$

over the $n$th discretised

time $(\operatorname{pax} / \Delta t)$ upper limit of the mean waiting time of the users in the queue $(\Delta t)$

global mean waiting time in the queue at the $i$ th platform over the $n$th discretised time $(\Delta t)$

\section{Maintenance policy parameters:}

age reduction coefficient after a maintenance action. To this work: the corrective maintenance policy is a minimal repair action to a failed component, thus $\alpha=1$; and the preventive maintenance policy is an imperfect action, $\alpha=\left\{\alpha_{p 1}, \alpha_{p 2}\right\}$, with $\alpha_{p 1}$, $\alpha_{p 2} \in(0, \ldots, 1)$, where $\alpha_{p 1}$ and $\alpha_{p 2}$ are the age reduction coefficient of a major maintenance and a minor maintenance stochastic hazard rate related to a human and technical uncertainty over a maintenance action relationship between the quantity of minor maintenance actions per major maintenance action probability and cumulative fault distribution, respectively rate of cycles made by the $j$ th component in the $n$th discretised time (cycles/ $\Delta t$ )

working cycles of the $j$ th component (cycles) reliability of the $j$ th component and global reliability of the system (cycles), respectively lower limit of the global reliability of the system (cycles) 


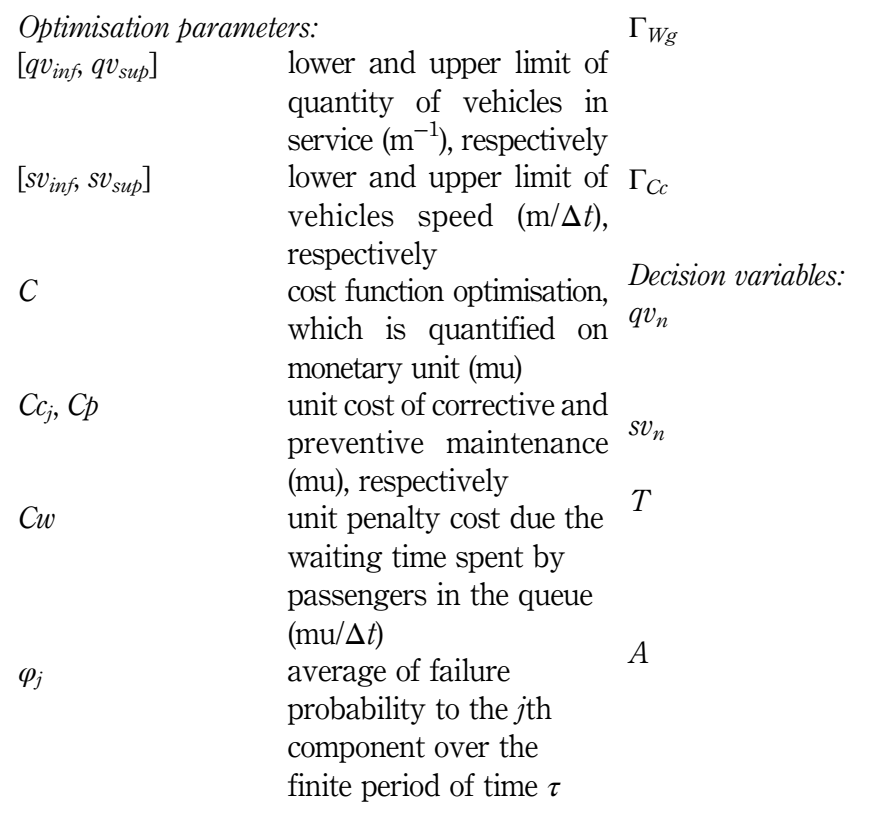

global penalty cost due

to the waiting time

spent by passengers

in the queue (mu)

global cost of corrective

maintenance $(\mathrm{mu})$

density of vehicles

over the $n$th discretised

time $\left(\mathrm{m}^{-1}\right)$

vehicles speed in the

$n$th discretised time $(\mathrm{m} / \Delta t)$

quantity of partitions

(periodicity) of preventive

maintenance based on a

periodic block-type

range of working cycles

between age-based

preventive maintenances

\section{Introduction}

The effective integration of maintenance and service policies with engineering in the organisation can help to save huge amounts of time, money and other resources in dealing with reliability, availability, maintainability and performance issues (Moubray, 2003). Reliability and maintenance are crucial to the success and long-term future of an organisation (Fraser et al., 2015). For most organisations it is now imperative that they take opportunities via maintenance management programmes to optimise their productivity, while maximising the overall equipment effectiveness (Fraser et al., 2011). Poor systems performance, downtime and ineffective planning maintenance lead to the loss of service, increased costs and decreasing profit (Cholasuke et al., 2004); on the other hand, companies that can effectively infuse the maintenance function into its primary activities will save time, money and other resources in dealing with reliability, availability, maintainability and performance issues (Fraser et al., 2015).

For some critical sectors such as energy, water, health and transport, maintenance takes on an even greater importance (Fraser et al., 2011). An important problem in these sectors is the long-term maintenance scheduling of systems and equipment. Maintenance scheduling outages have a great effect on the system availability and service cost. There are some studies that consider the integration of maintenance and service policies for the critical sectors. Henceforward, we present some works focused on energy and productive sectors. Alardhi et al. (2007) described a method developed to schedule the preventive maintenance tasks in separate and linked cogeneration plants while satisfying the maintenance and production constraints, which finds the maximum number of available power and desalting units. Souheil et al. (2012) proposed an optimal plan with a preventive maintenance policy aiming at reducing the machine degradation while minimising the total cost (production, inventory and maintenance costs). Later, Hajej, Dellagi and Rezg (2014) and Hajej, Turki and Rezg (2014) dealt with the problem of jointly optimising maintenance, production and inventory costs considering subcontracting and 
product returns. A detailed study of the literature of maintenance management applied to energy and productive sectors is provided by Fraser et al. (2015).

An effective scheduling can save considerable operational costs that help electric, water to be more competitive in terms of availability of resourrees while increasing system reliability (Alardhi et al., 2007). The reliabilities of critical sectors, specifically the urban transport, have become increasing important issue in large cities. A deficient public transport system due to unexpected failure is the cause of increasing customer and society dissatisfaction in cities around the world (Fraser et al., 2011).

The conventional urban transport systems (e.g. traditional bus, streetcar, subways, bus rapid transit, light rail transit) serve travel patterns in urban areas with strongly focused travel patterns and available space (whether underground or level-ground); however, different urban contexts with wide range of geographical and topographical conditions (e.g. mountains, valleys, bodies of water) do not permit the implementation of conventional public transportation. Urban ropeway systems are a technology that grows significantly to serve the travel patterns of geographically constrained areas in which conventional transit service was deemed very difficult or infeasible to implement (Alshalalfah et al., 2014). Ropeways play an irreplaceable role in many areas as a special mean transport for a long time. As a subsystem of a transport system, ropeway transport holds a specific place because it makes accessible those places that are interesting from the aspect of tourism and/ or economic activity as well as urban areas that are difficult to access via other transport subsystems (Sever, 2002).

The urban ropeways are geographically located in urban areas and serve public transport needs. The urban ropeway transport systems are specific in the sense that the integration into the urban landscape as well as the operating conditions of public transport (transport volumes, operating hours) constitutes specific challenges (Reichenbach and Puhe, 2018). These installations have greatly increased the accessibility of existing settlements, which had not been served by public transport before, or build a more efficient alternative to former queues of busses stuck in traffic (Reichenbach and Puhe, 2018).

In cities with hills, the ropeways offer an attractive, straightforward and reasonably priced system for mainstream urban public transport. Ropeway systems provide not only a convenient transportation in hilly terrains, over rivers, harbours and motorways, but also an alternative to connect people over densely populated residential areas (Alshalalfah et al., 2012). Currently, ropeway systems are becoming a popular transport mode and a logical choice for their ability to efficiently move passengers from the tops of hilly metropolitan areas to lower-lying areas. In this way, the ropeways are often the critical initial piece of the system, bringing passengers down to valley areas where they can access other transport modes in the wider integrated urban transport network. The use of ropeways in urban contexts, fit into public transport networks and tariff schemes just like any other means of public transport, is a phenomenon of accessibility, which becomes a central driver in the development and analysis of transport policies (Prestonand Rajé 2007). A growing number of urban ropeway installations in worldwide has been used as parts of the public transport network in larger cities, including for example (Bocarejo et al., 2014; Heinrichs and Bernet, 2014; Težak et al., 2016): North America in New York (USA), Portland (USA), Roosevelt Island (USA), Mexico D.F. (Mx); Latin America in Rio de Janeiro (Br), Medellín (Co), Cali (Co), Manizales (Co), Caracas (Ve), La Paz (Bo); Europe in Nizhny Novgorod Bor (Ru); Asia in Taipei Maokong (Tw), Hong Kong, Ankara (Tr); and Africa in Constantine (Dz).

Urban aerial cableways for mass transport, operations are permanent (near $24 \mathrm{~h}$ a day) and maintenance operations can no longer be carried out during large non-use ranges (as it is the case for winter sports tourist usage). It is therefore necessary to propose a combined approach so that maintenance operations have balanced impact on the operational effectiveness of the facility, i.e., availability increase related to the time dedicated to 
maintenance operations. In this paper, the proposed work analyses the demand for transport, for an optimal service-oriented maintenance plan; thus, the maintenance policy represents a set of parameters to qualitatively evaluate the proposed solution. Other work (Martinod et al., 2018) proposes a stochastic optimisation model in order to reduce the long-term total maintenance cost of complex systems considering several maintenance policies, but does not take into account the service-operational policy. The lack of studies evaluating service performance, as impacted by maintenance requirements, provided a motivation for the research. In particular, the authors found few studies dealing with the simultaneous optimisation of maintenance and service policies in urban ropeway transport systems. An efficient service should consider the waiting time of users, but on the operational side, decreasing the waiting time increases the cost of service in terms of maintenance actions. The contributions of this work are as follows:

(1) to the best of our knowledge, this is the first study to simultaneously consider maintenance policy and operational policy in an urban aerial ropeway system, taking up the problem of queuing with particular attention to the unique requirements public transport services;

(2) this work analyses ropeway system maintenance and operational polices based on the international regulations, evaluating how fluctuating demand influences the operating conditions; and

(3) this paper proposes a method to establish passenger waiting time in relation to the optimal maintenance policy for an optimal urban transport service. The approach has been developed specifically to take into account passenger demand in urban public ropeway systems.

The paper is organised as follows. Section 2 summarises the relevant literature concerning to urban transport studies based on the service policy. Section 3 sets out the mathematical expressions of service and maintenance policies applied to ropeway system operation. In Section 4, a stochastic optimisation model is developed to obtain the optimal service and maintenance actions. The model is applied in Section 5 using an example focused on an urban ropeway system. Finally, Section 6 concludes the paper and discusses

Q4 future research. Nomenclature shows the coefficients, parameters and variables used throughout the paper.

\section{Literature review}

Studies of passenger transport demand in urban public transport systems have increased with a renewed recognition of their role in the economic development of cities. In recent years, transport planning has evolved to place greater emphasis on urban transport to increase the mobility of commuters (Ibarra-Rojas et al., 2015; Shang et al., 2016; Li and Sheng, 2016).

Previous works have had different approaches for analysing passenger demand in urban transport systems. Using a dynamic systems approach, Horn (2002) showed a demand-responsive passenger transport system based on a model to analyse the performance of urban passenger transport. By means of an economic theory-based approach, Ison and Sagaris (2016) examined the social, political, regulatory and operational challenges in providing urban transport. Using a scheduling-based approach, Wang et al. (2015) proposed an event-driven model involving different types of events to obtain a nonlinear nonconvex optimisation problem. There are also studies (Barrena et al., 2014a; Sun et al., 2014) focusing on a non-periodic timetable that explicitly considers timedependent passenger demand to reduce waiting time and travel time. Other works (Niu and Zhou, 2013; Barrena et al., 2014b) reduced the waiting time of passengers looking into the 
arrival process of passengers in stations with a uniform process or a Poisson process. A detailed review of these approaches is provided by Yin et al. (2017).

There has also been a research focus on waiting and queuing phenomena associated with urban transport services, with studies showing that urban transport users are negatively inclined if it involves uncertain waiting time (Ceder et al., 2013). Nesheli et al. (2015) introduced synchronised timetables to reduce the waiting time caused by batch arrivals. Queues with batch arrivals and bulk service are commonly observed in the field of behaviour in transport systems, and such queues are found with urban buses, trains, trams, railways or ropeways. The queuing process follows the following features (Wang et al., 2014): passenger demand at urban transport terminals consists of people gradually arriving in batches, with demand increasing progressively until rush hour, and then declining in the off-rush hour; and the service has a bulk-like pattern, given that it is a mass-transport service. Passengers arrive in batches to a terminal where they can be served en masse for the transport system. This paper therefore assumes an urban transport system characterised by batch arrivals and bulk service patterns.

Queuing theory applications in transport has led to a number of author to develop queuing systems (Ceder et al., 2013): arrival patterns of passengers - e.g. Poisson, Erlang, Gaussian and others; service patterns; queue discipline - e.g. first-come-first served, priority-based; number of servers provided; maximum queue length allowed; and configuration of the transport operators - e.g., in series, in parallel or mixed. In this work, the theory of compound Poisson processes is used to establish a stochastic model of passenger demand in the stations. The distribution of arrival passengers is obtained with the classes defined by the quantity of users per time unit on the frequency domain (e.g. passengers/minute). Thus, the density distribution function of passenger arrivals follows a Poisson distribution (Dalla-Chiara, 2010); in consequence, it is possible to apply the queuing theory, which allows us to evaluate the quality of requested service.

Some authors (May and Keller, 1967; Hall, 2003) have argued that queues in the transport field often tend to be deterministic and predictable because of: the passengers journey generates demands for repetitive patterns; and queues by random variations in arrivals and service are often deemed to be secondary relative to queues caused by predictable demand patterns. In response, another line of research (Lee and Vuchic, 2005; Nesheli et al., 2015) has defined urban transport attributes as stochastic (e.g. travel time, dwell time, passenger demand, etc.). Ceder (2007) used a formulation for mean passenger waiting time under the assumption of random passenger arrivals, and Newell (1977) assumed that the passengers arrive at stops according to a Poisson distribution and the delay of vehicles according to Fokker-Planck. The hybrid queue-based model of Wu and Mengersen (2014) reflected a Bayesian Network model and stochastic queuing theory, using the properties of the Poisson and exponential distributions. The theory of compound Poisson process is introduced as the main model to deal with the queuing problem on urban public transport (Ceder et al., 2013). Moreover, transport queuing models have been characterised as non-stationary (time varying) systems (Lee and Vuchic, 2005; Parbo et al., 2014).

Following similar lines, several optimisation models have been developed. Lee and Vuchic (2005) proposed an optimal transit system as a compromise among the minimal travel time, the transit operator profit and minimisation of social costs. Parbo et al. (2014) dealt with timetable optimisation from the perspective of minimising the waiting time experienced by bus passengers; the researchers obtained a bi-level minimisation problem via a nonlinear nonconvex mixed-integer problem. Yin et al. (2017) studied a dynamic passenger demand in the context of railway scheduling with the goal of minimising the operational costs and passenger waiting time, resulting in a mixed-integer linear programming problem.

Pitsiava-Latinopoulou and Iordanopoulos (2012) is noteworthy for introducing a categorisation of urban transport terminals based on journey features. Intercity terminals 
are transit points for passengers travelling relatively long distances between cities or countries, where the chief characteristic is long waiting times and a lack of significant traffic fluctuations. At commuter transit centres, the passengers are regular travellers who need advanced accessibility and minimum travel time (Sun et al., 2017); the main feature is the large variation in hourly demand during the day and the need for a quick and convenient transfer between transport modes (Jones et al., 2000). Interchanges are intermodal facilities established at connection points for different transport modes forming a co-operative urban transport network. Park-and-ride terminals function as stations designed to provide adequate parking, primarily at urban transport terminals (Spillar, 1997). Finally, there are on-street facilities, public transport stops that serve different routes or transfers between different modes. The present work is focused on park-and-ride terminals and on-street facilities, as they are the more typical terminals for the integration of passengers into an urban transport network via ropeway.

\section{Problem description}

This section describes the problem by analysing the characteristics of each policy separately: urban transport service policy, and ropeway system maintenance policy; as follows.

\subsection{Urban transport service policy}

The distribution of passengers who arrive at a ropeway station is obtained by the quantity of users per time unit in the frequency domain (e.g. pax/min), the probability distribution of arrivals on the $i$ th platform over the $n$th instant of time belongs a Poisson distribution, $P a_{i, n}$ $(\mathrm{pax} / \Delta t)$ (Gillen and Hasheminia, 2013), the empirical distribution of the passenger arrivals has been verified using a goodness-of-fit test (Dalla-Chiara, 2010). According to the queuing behaviour of ropeways, the best model for evaluating waiting time is expressed as $\mathrm{M} / \mathrm{M} / 1$ / $\infty /$ FIFO (Jenelius, 2018). This work assumes the following conditions about service policy and context:

Assumption 1. Passengers arrive at the upper ropeway station in order to reach the downtown or connect to another transport mode by means of a transfer station at the bottom of the hill (railway, light-train, bus, etc.).

Assumption 2. The stations are characterised by having on-street facilities.

Assumption 3. Passengers do not use another transport mode before their arrival at the upper ropeway station.

Assumption 4. If the number of waiting users exceeds the capacity of the ropeway system, the operator leaves behind some passengers - just as in any other transportation mode (Kahraman and Gosavi, 2011). The system has therefore a finite capacity to serve users. The demand rate may exceed the capacity of the system in some periods.

Assumption 5. The urban transport service policy must correspond to the demand placed upon the system. There must, in other words, be flexibility in the service, allowing it to adapt to variations in demand (Amirgholy and Gonzales, 2016).

Given a Poisson process as probability function of discrete-time and linearly spaced, the sequence $n=\{1,2, \ldots, N\}$ with $n \in t$ is used to represent the time sequence between successive events. The discrete-time stochastic distributions make it possible quantify the number of users over a finite set of events. The events depend on the arrival of vehicles on the platform. Using an operative characteristic of the ropeway system (all vehicles are synchronised by the pulling cable, and the vehicles 
speed, $s v_{n}$, has a constant value over the periods of operation), the discrete-time period can be written as follows:

$$
[n, n+1]=\Delta t=\frac{l v_{n}}{s v_{n}},
$$

Q6

where $l v_{n}$ is distance between vehicles (see Figure 1(a)).

The weighted mean of arriving passengers on the $i$ th platform over the $n$th event is represented by $\lambda_{i, n}(\operatorname{pax} / \Delta t)$, with $i=\{1,2, \ldots, I\}$. It can be expressed as a probability function at the $i$ th platform, $P a_{i, n}$, over a period of time $[a, b]$ by means of $\lambda_{i, n}=(b-a)^{-1} \sum_{n=a}^{b} P a_{i, n}$, with $a<b$. Using an analogous definition, the average of effected services during the same period of time is given by $\sigma_{i, n}=(b-a)^{-1} \sum_{n=a}^{b} P e_{i, n}$, where $P e_{i, n}$ is the probability function of disembarking passengers. If the period of time is $[a, b]=N$, and $N$ is defined as a typical service period of time (e.g. full working day), the service capacity of the platform must not overflow in order to ensure the complete outflow of the passengers from the system; i.e., a stability condition of the service must be guaranteed, where $\sum_{n} \lambda_{i, n}\left(\sum_{n} \sigma_{i, n}\right)^{-1} \leqslant 1$.

Remark 1. Note that $\sigma_{i, n}$ relies on the capacity of the transport system. This means $\sigma_{i, n}$ $(\operatorname{pax} / \Delta t)$ is directly related to both variables: the frequency of passing vehicles in service $f v_{n}\left(\mathrm{~s}^{-1}\right)$ (in the case of ropeway systems, all vehicles have the equivalent of $f v_{n}$ value in each instant $n$, because pulling cable synchronises the separation - distance - between vehicles), and the quantity of available places in the $k$ th vehicle $g_{k, i, n}$ (pax), with $k=\{1,2, \ldots, K\}$; thus, $\sigma_{i, n}=f v_{n} g_{k, i, n}$. Moreover, $f v_{n}$ can be expressed according to the density of vehicles $q v_{n}$, and the vehicles speed $s v_{n}$, i.e.:

$$
f v_{n}=s v_{n} q v_{n} .
$$

(a)

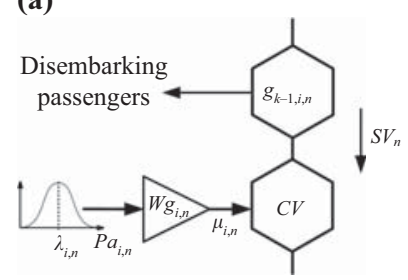

(b)

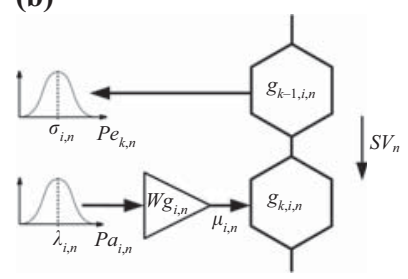

(c)

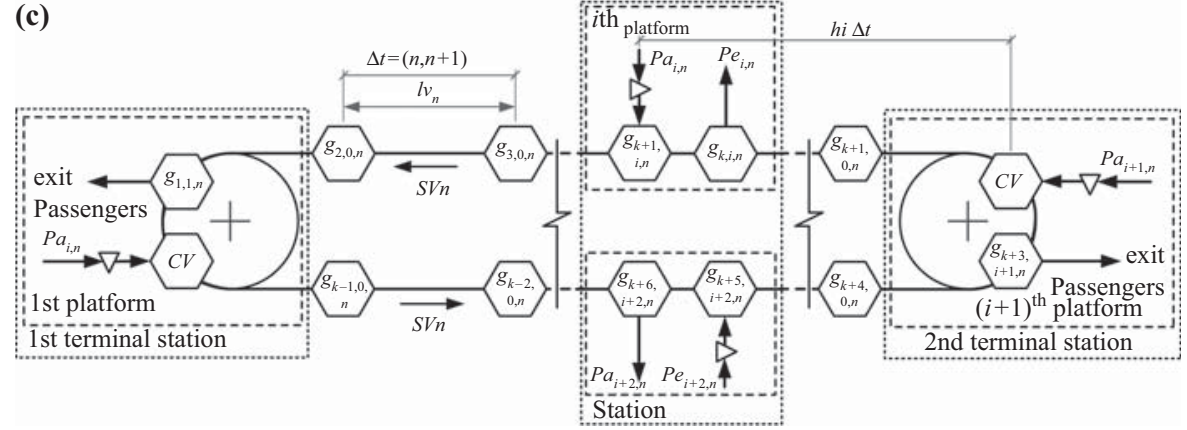

Notes: (a) Queuing model of a terminal station; (b) queuing model of the $i$ th platform; (c) general diagram of urban ropeway systems

Figure 1.

Service model of ropeway systems 
Two different boarding/disembarking models are considered for the queuing model to describe the service behaviour of a typical ropeway system.

The first model describes the boarding/disembarking process on the single platforms (see Figure 1(b)) belonging to stations between the loops of the line. The model is based on a stochastic service. The service on a platform directly depends on the service behaviour of the previous platform, i.e., $\mu_{i, n}$ depends on $g_{k, i, n}$. From the point of view of users in the queue, the vehicles in service have different (random) sizes because user is interested in the available places in the vehicle.

The second model describes the process for boarding/disembarking at terminal stations, located at the ends of the line. This model is based on constant service time (see Figure 1(e)), i.e., the service is constant and established by the operational characteristics. This service behaviour takes place according to two different operating conditions: cases in which the ropeway system starts operating, and each vehicle is empty in order to pick up passengers; and cases in which the $k$ th vehicle is located in one of the system's terminal stations (passengers have finished their journey and just disembarked).

According to the both boarding/disembarking models, the quantity of users in the queue on the $i$ th platform is as follows:

$$
L q_{i, n}=\left\{\begin{array}{ll}
L q_{i, n-1}+\lambda_{i, n}-\mu_{k, i, n} ; & \text { if first queuing model } \\
L q_{i, n-1}+\lambda_{i, n}-c v ; & \text { if second queuing model }
\end{array},\right.
$$

and $\mu_{k, i, n}=g_{k, i, n-h}+\mu_{k, i-1, n-h}-\sigma_{k, i-1, n-h}$, with $\mu_{k, i-1, n-h}$ representing the quantity of passengers who board the $k$ th vehicle at the platform before (the vehicle spend $h_{i}$ times of discrete-time period $\Delta t$ to transit between stations), and $\sigma_{k, i-1, n-h}$ representing the quantity of passengers who disembarked from the $k$ th vehicle on the preceding platform:

$P 1$. The general formulation to the mean waiting time is expressed as follows:

$$
W g_{n}=\frac{1}{s v_{n} q v_{n}} \sum_{i} \frac{L q_{i, n}}{\mu_{i, n}}
$$

Proof 1 . By definition, the average waiting time for each platform depends on the ratio between the quantity of users in the queue, $L q_{i, n}$, and the users leaving the queue to board the vehicle, $\mu_{i, n}$, adjusted for time they spend waiting in the queue, i.e.:

$$
W g_{n}=[n, n+1] \frac{L q_{i, n}}{\mu_{i, n}} ; \quad \forall i=\{1,2, \ldots, I\} ;
$$

therefore, the total weighted waiting time in the railway system is the sum of the values on all platforms:

$$
W g_{n}=[n, n+1] \sum_{i} \frac{L q_{i, n}}{\mu_{i, n}},
$$

then, taking Equation (1) and considering that $\Delta t$ is equivalent to the inverse of the passing vehicles frequency $f v_{n}{ }^{-1}$ :

$$
W g_{n}=\frac{1}{f v_{n}} \sum_{i} \frac{L q_{i, n}}{\mu_{i, n}},
$$

taking into account Equation (2) the proposition is proved. 
The discrete-event model deals with the analysis of the waiting lines with the objective of determining $W g_{n}$ value, which changes only when the passengers board the vehicle, $\mu_{i, n}$ - and simultaneously other passengers disembark from the previous vehicle, $\sigma_{k-1, n}$. In other words, the proposed model is a composite of queues from a set of stochastic distributions $\left\{P a_{i, n}, P e_{i, n}\right\}$. Therefore, only $n$ is required to examine the transitory behaviour of the system, and other time points do not affect the data relating to system operation. In Section 3.1., we will develop the formulation of the service problem regarding to the service parameters behaviour $\left(s v_{n}, q v_{n}\right)$.

\subsection{Maintenance policy of ropeway systems}

Technical regulations govern the requirements for passenger installations by cable drives. Directive 2000/9/EC (2000) standardises ropeway installations designed to carry persons (e.g. funicular railways, cable-cars, gondolas, chairlifts and drag lifts) and which are designed, manufactured, put into service and operated for the purpose of transporting passengers safely. The international standard BS/EN-1709 (2004) establishes general guidelines in relation to the inspection and maintenance required on the component systems: vehicles; carrier cables and pulling cables; electro-mechanical devices; traction and brake equipment; rescue, monitoring and signalling devices; and installation and infrastructure. Moreover, there are two types of components associated with any ropeway system: a set of mobile components which are driven by the pulling cable - such as the vehicle and its parts - that are influenced directly by $s v_{n}$; and a set of structural components, such as supports, installation and infrastructure, that are influenced directly by both: $s v_{n}$ and $q v_{n}$.

Remark 2. As part of the safety systems governing installations like ropeway systems, periodic preventive maintenance has been introduced as a technical specification on an industry-wide basis. The maintenance managers of ropeways have adopted a periodic preventive maintenance based on a periodic block-type maintenance policy, which provides for maintenance actions to be carried out according a fixed schedule based on linearly spaced periods of chronological time.

The number of working cycles, $\omega_{j}$, produces wear-out of the $j$ th component; thus, the ratio of cycles, denoted as $r_{j, n}$ (cycles/s), defines the rate of deterioration for the $j$ th component:

P2. The ratio of cycles is expressed as follows:

$$
r_{j, n}=\left\{\begin{array}{ll}
\frac{2 I s v_{n} q v_{n}}{\sum_{i} h_{i}} ; & \forall j \text { if } u=0 \\
\frac{l v_{n} s v_{n} q v_{n}^{2}}{\sum_{i} h_{i}} ; & \forall j \text { if } u=1
\end{array} ; \text { with } u=\{0,1\},\right.
$$

where $u=0$ in the case where the $j$ th component be a mobile component, $u=1$ in the case where the $j$ th component be a structural component and the value $I$ is the quantity of platforms.

Proof 2. Consider the $j$ th component as a moving component by the pulling cable; then, the component undergoes two cycles each time a platform is crossed (a first cycle entering the platform, and a second cycle leaving the platform), i.e. the quantity of cycles that are applied to a component during a loop journey is $2 I$ (cycles); moreover, the spent time by a vehicle for whole loop journey is $\Delta t \sum_{i} h_{i}(\mathrm{~s})$; therefore:

$$
r_{j, n}=\frac{2 I}{\Delta t \sum_{i} h_{i}} ; \quad \forall j \text { if } u=0,
$$


then, taking Equations (1) and (2) into Equation (9), the first part of the proposition is proved. Now, consider the $j$ th component as a structural component belonging to the ropeway system. The component undergoes a single cycle each time a vehicle crosses the component; i.e., the quantity of cycles that are applied to a component during a loop journey is $q v_{n} l v_{n}$ (cycles); therefore:

$$
r_{j, n}=\frac{q v_{n} l v_{n}}{\Delta t \sum_{i} h_{i}} ; \quad \forall j \text { if } u=1
$$

again, taking Equations (1) and (2) into Equation (10), the second part of the proposition is proved.

Remark 3. Note that the operational parameters, $q v_{n}$ and $s v_{n}$, define the quality level of service $W g_{n}$, and the degree of deterioration in the ropeway components as well, $r_{j, n}$.

Figure 2(a) shows the relationship between $r_{j, n}$ and the two types of components (mobile and structural) over a typical service time $N$, which is classified by periods of users demand, $m=\{1,2, \ldots\}$, where $m=1$ represents the users demand of full rush hour, and $\forall m \neq 1$ represents the users demand of a partial rush hour. Considering the periods of users demand for the ropeway system, the performed working cycle by the $j$ th component can be expressed as $\omega_{j}=\Delta t \sum_{n} r_{j, n}$.

Let $f_{j}$ be defined as the fault probability distribution of the $j$ th component - working cycles per fault ( $\omega /$ faults) - (see Figure $2(\mathrm{~b}))$ and $F_{j}$ as the cumulative distribution function corresponding to $f_{j}$ on a determined working cycle $\omega_{j}, F_{j}\left(\omega_{j} \leqslant \omega\right)$, see Figure 2(c). The probability of reliability for each $j$ th component in the transport system is $R_{j}=1-F_{j}$ with

(a)

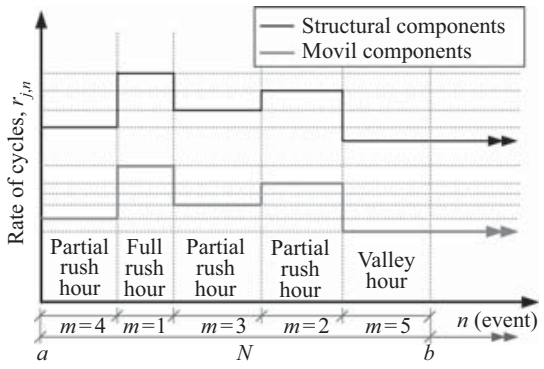

(c)

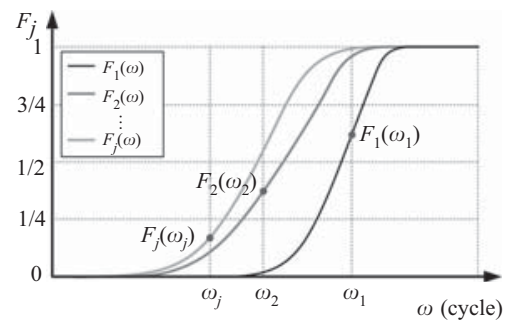

(b)

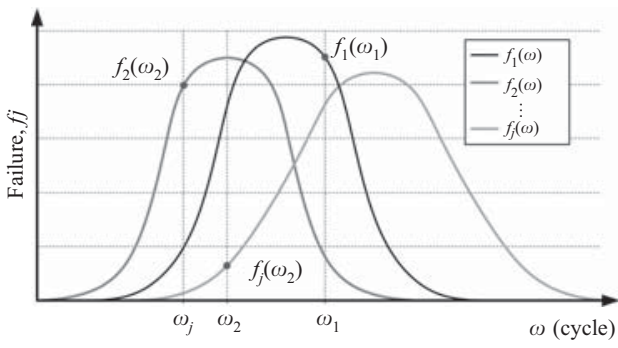

(d)

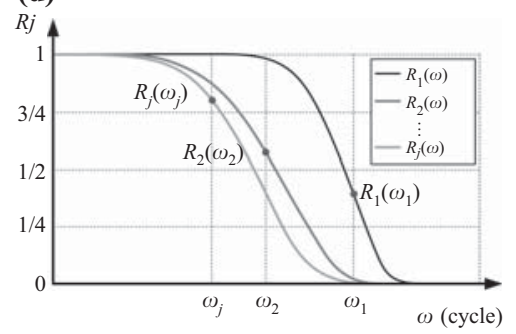

Notes: (a) Rate of cycles to different type of components; (b) fault probability functions; (c) cumulative fault probability functions; (d) reliability probability functions
Urban ropeway transport systems

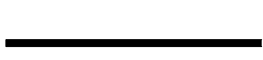


$j=\{1,2, \ldots, J\}$ (see Figure 2(d)). The global reliability of the system, $R g$, is directly relied on the behaviour of $R_{j}$ as follows:

$$
R g=\left\{\begin{array}{ll}
\prod_{j} R_{j} ; & \forall j \text { if } u^{\prime}=0 \\
1-\prod_{j}\left(1-R_{j}\right) ; & \forall j \text { if } u^{\prime}=1
\end{array} ; \text { with } u^{\prime}=\{0,1\},\right.
$$

where $u^{\prime}=0$ in the case where the $j$ th component be in a series relationship configuration over the system, i.e. a failure of the any $j$ th component will result in a failed function in the whole system; and $u^{\prime}=1$ in the case where the $j$ th component is in a parallel relationship configuration over the system, i.e. the system performs as long as a single $j$ th component remains operational.

Ropeway maintenance managers may adopt different maintenance policies regarding the repair actions on a failed component ahead of the next scheduled preventive maintenance. The repairing actions affect the technical state of the repaired component in terms of its workinglife (2013), i.e. $\alpha \omega_{j}$, with $0 \leqslant \alpha \leqslant 1$, where $\alpha$ is the age reduction coefficient after the maintenance action. In case the maintenance manager adopts a maintenance policy with a value $\alpha=0$, the reliability level of the component takes the nominal value $R_{j}=1$, and the working cycles is restored to $\omega_{j}=0$. This means that the corrective actions are focused on a perfect repair bringing the component to as-good-as-new condition (AGAN). AGAN involves repairing the component using the required resources to obtain the highest repair quality of the component. But, in a case where maintenance management adopts a maintenance policy with a value $\alpha=1$, the reliability level of the component remains the value before the fault $R_{j}\left(\omega_{j}\right)$, meaning that the corrective actions are focused on a minimal intervention to the component, entitled as-bad-as-old (ABAO), which consists in repairing the component using the minimum possible resources to obtain the working component again (Hajej et al., 2012; Martinod et al., 2018). In Section 3.2., we will develop the formulation of the maintenance policy problem regarding to the imperfect preventive maintenance.

\section{Proposed model}

There are two different methodologies available to address the problem: an aspirationlevel model, which works directly with the measure of the queuing performance with the goal of determining an acceptable range for the service level, $\mu_{i, n}$, by specifying reasonable limits on the queuing performance (the limits represent the aspiration level); and a cost-based model, which attempts to balance two conflicting costs: the cost of offering an efficient service, and the cost of delaying the service offer (passengers waiting time). The two types of cost are in conflict because any increase to one automatically affects the other. Both approaches recognise that higher service levels reduce the waiting time in the system, and both models aim to strike a balance between service level and waiting time (Taha, 2011). The proposed work is focused on the cause-effect relationship between the joint service-operational policy and the maintenance policy, a relationship developed in the context of the cost-based model optimisation analysis: penalty cost for passengers waiting time, and maintenance activities cost.

The paper tackles the problem by developing the formulation in three stages: formulation of the service; formulation of the maintenance, which is analysed by two different strategies, i.e.corrective and preventive; and formulation of the combined service-maintenance policies.

\subsection{Development formulation of the service problem}

A discrete-time model is used to describe the queuing situations, in which the passengers: demand the system, $\lambda_{i, n}$; wait in a queue, if necessary, $W g_{n}$; receive the service, $\mu_{i, n}$; and 
arrive at their destination, $\sigma_{i, n}$. The discrete-time model is composed of a set of interrelated queues with the objective of determining $W g_{n}$ value.

Urban ropeway

Remark 4. Note that the $W g_{n}$ value constitutes a penalty cost. The methodologies to quantify the penalty cost are directly defined by the operation managers of the ropeway systems. Each can use different criteria to quantify the penalty cost according to its service policy.

In this paper, the relationship used to describe the penalty cost for waiting time is expressed as $C w(\mathrm{mu} / \Delta t$ ) (see Figure 3(a)); thus, the penalty cost for the global waiting time is defined as follows:

$$
\Gamma w g=C w \sum_{n} W g_{n}
$$

Remark 5. This work assumes that $\Gamma w g$ is described as a linear function, where the $C w$ value is a constant linear rate. The linear function is adopted because it is efficient and appropriately describes the cost for passengers waiting time. The task of building on these assumptions will be part of future works, according to the correlations highlighted in the literature review.

Section 4.2 will develop an application example of the service parameters behaviour regarding to the penalty cost by $\Gamma w g$.

(a)

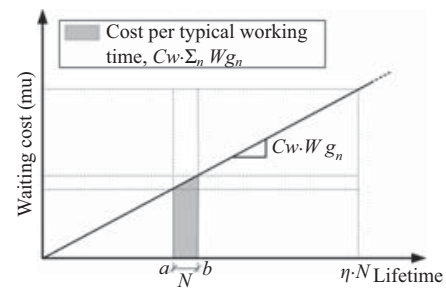

(c)

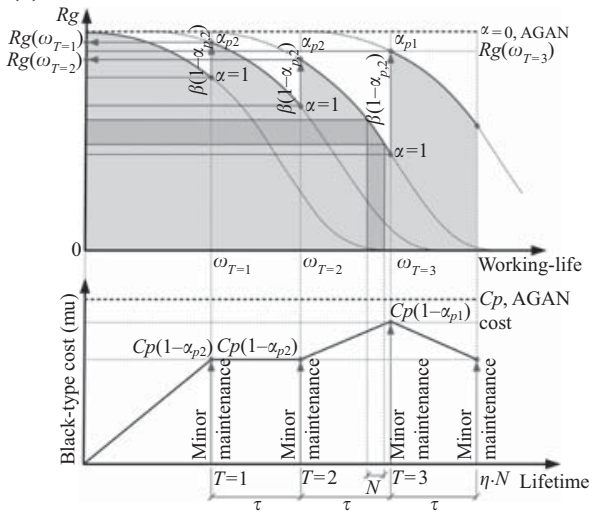

(b)

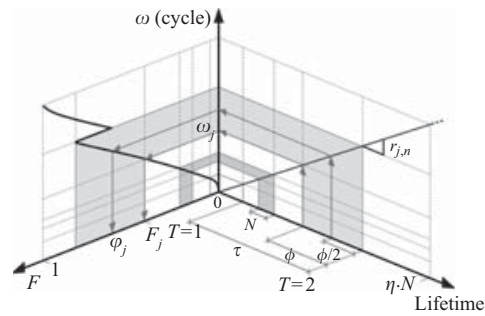

(d)

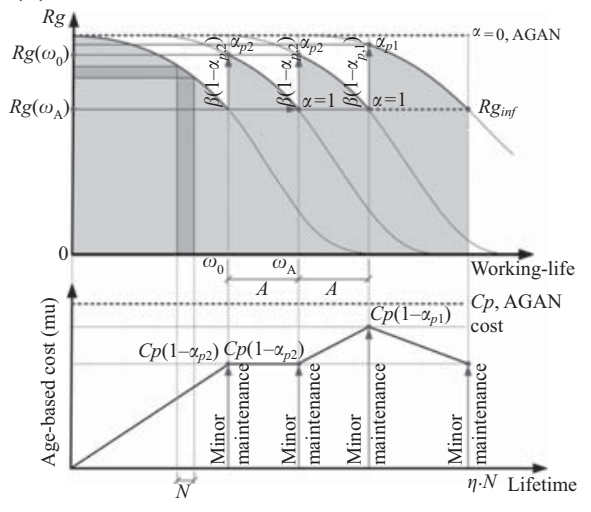

Notes: (a) Waiting cost relationship; (b) corrective maintenance parametrization; (c) periodic block-type preventive; (d) age-based preventive maintenance

Figure 3.

Relationship of maintenance policy parameters 


\subsection{Development formulation of the maintenance problem}

The maintenance actions and their associated cost are a well-known topic for ropeways maintenance managers, who must assess the relative merits of preventive vs corrective maintenance policies.

4.2.1 Formulation of corrective maintenance. The repairing actions on a failed component are executed between the scheduled preventive maintenances, i.e. between the working cycles range $A_{j}=\omega_{A}-\omega_{o}$ (see Figure 3(b)); in addition, the repairing actions have a cost associated for the fault of the $j$ th component, which is expressed as a cost value on monetary unit, $C c_{j}(\mathrm{mu})$ :

Remark 6. The corrective maintenance policy (commonly used by the maintenance managers) corresponds to ABAO (Pham and Wang, 1996; Khatab et al., 2013; Knezevic et al., 2017). This work adopts an ABAO corrective maintenance policy, which is defined by the age reduction coefficient $\alpha=1$, i.e. the $R_{j}$ value, before the fault, remains (Martinod et al., 2018).

P3. The cost of the corrective maintenance, $\Gamma c$, is expressed as the sum of the cost for the fault of the components affected by their probability of fault, $\varphi_{j}$ :

$$
\Gamma c=\sum_{j} C c_{j} \varphi_{j}
$$

where $\varphi_{j}$ is the average failure probability for the $j$ th component, from the current lifetime, $\omega_{j}$, to the next preventive maintenance action, $\omega_{A}$.

Proof 3 . The fault probability of the $j$ th component is quantified by the mean area value from the probability function of fault distribution:

$$
\varphi_{j}=P\left(\omega_{j} \leqslant \omega \leqslant \frac{\omega_{j}+\omega_{A}}{2}\right)=\left(\omega_{A}-\omega_{j}\right)^{-1} \int_{\omega_{j}}^{\omega_{A}} f_{j}(\omega) d \omega,
$$

with $\omega_{j}<\omega_{A}$. In addition, the probability average value of the function of fault distribution can be expressed by the mean value of the cumulative fault distribution:

$$
\left(\omega_{A}-\omega_{j}\right)^{-1} \int_{\omega_{j}}^{\omega_{A}} f_{j}(\omega) d \omega=F_{j}\left(\omega_{j}+\frac{\omega_{A}-\omega_{j}}{2}\right) .
$$

If the relationship $\omega_{j}+\left(\omega_{A}-\omega_{j}\right) / 2$ is denoted as $\phi_{j}$, it is possible to express $F_{j}\left(\phi_{j}\right)=\varphi_{j}$; then, the probability of fault, which affects $C c_{j}$ to get the corrective maintenance cost actions, has been proved.

4.2.2 Formulation of preventive maintenance. The preventive maintenance actions are adjusted to improve the $R g$ value. The imperfect preventive maintenance is well established in the field of engineering (Hajej, Dellagi and Rezg, 2014; Hajej, Turki and Rezg, 2014; Hajej et al., 2015; Umamaheswari et al., 2018) and has been the preferred approach of the maintenance managers of ropeways (Martinod et al., 2018); therefore, the imperfect preventive maintenance is considered in this study, which is defined by the age reduction coefficient, $0<\alpha \leqslant 1$ (Alaswad et al., 2017; Knezevic et al., 2017). After each preventive maintenance action, the equipment is restored on a lower level than the nominal state of its components, i.e. over the lifetime of the system its components undergo wear and degradation.

Let us define the highest quality maintenance cost as $\operatorname{Cmax}_{j}(\mathrm{mu})$, which is the cost of the required resources to carry out AGAN maintenance. In other words $C_{\max }$ represents the 
cost of the required resources to get the highest quality maintenance and to restore the reliability function of the component to its nominal value, $R_{j}=1$. As a consequence, when the budget of a maintenance action for the $j$ th component is equivalent to $C \max _{j}$, the executed maintenance action consists of replacing the component with a new one; hence, the value of the age reduction is restored, $\alpha=0$ (Martinod et al., 2018).

The cost of the imperfect maintenance action is a fraction of $\mathrm{Cmax}_{j}$, which is directly related to the age reduction coefficient of the component; thus, the cost of a preventive maintenance action can be expressed as $\operatorname{Cmax}_{j}(1-\alpha)$. The preventive actions are classified according to two types: major maintenance and minor maintenance. The age reduction coefficient associated with the preventive maintenance action is $\alpha=\left\{\alpha_{p 1}, \alpha_{p 2}\right\}$, with $\alpha_{p 1}$ and $\alpha_{p 2} \in(0<\alpha \leqslant 1)$, where $\alpha_{p 1}$ is the age reduction after major maintenance action, and $\alpha_{p 2}$ is the age reduction coefficient after minor maintenance.

Remark 7. The cost of the major maintenance action is higher than the cost of the minor maintenance action, $C \max _{j}\left(1-\alpha_{p 1}\right) \gg \operatorname{Cmax}_{j}\left(1-\alpha_{p 2}\right)$, therefore $\alpha_{p 1} \ll \alpha_{p 2}$ :

P4. The cost of an imperfect maintenance action by the preventive maintenance policy is expressed as follows:

$$
C i_{j}=C \max _{j}\left(1-\frac{\alpha_{p 1}+p \alpha_{p 2}}{1+p}\right)
$$

Proof 4. By definition, the cost of the imperfect maintenance relies on the sum of the costs of maintenance actions executed over the period of operating service time; i.e., the cost of the major maintenance and all the minor maintenances over a full cycle of preventive maintenance is as follows:

$$
C i_{j}=\operatorname{Cmax}_{j}\left(1-\alpha_{p 1}\right)+C \max _{j} \sum_{p}\left(1-\alpha_{p 2}\right),
$$

thus, the relationship between the major and the minor preventive maintenances is defined by means of the parameter $p$, which describes the quantity of minor maintenance actions per each major maintenance action, where $1+p$ is a full cycle of preventive maintenance over the long-term horizon of time $\eta$; therefore the expression is write as follows:

$$
C i_{j}=\operatorname{Cmax}_{j}\left(\left(1-\alpha_{p 1}\right)+p\left(1-\alpha_{p 2}\right)\right),
$$

and after some algebraic manipulations the proposition is proved.

This work considers two preventive maintenance policies:

(1) The periodic block-type is the preventive maintenance policy adopted by the ropeways maintenance managers. Given a horizon of time expressed as $\eta$ with a piecewise linear distribution of time $T_{j}$ (see Figure 3(c)) the distribution of time over a full cycle of preventive maintenance is defined as $T_{j} \eta=1+p$. The cost of the periodic block-type maintenance policy is expressed as follows:

$$
\Gamma p=\sum_{j} T_{j} C i_{j} .
$$

(2) The age-based maintenance policy is executed as the reliability indices of the components reach a predetermined level (Wang, 2002; Alaswad et al., 2017), i.e. the system undergoes a preventive maintenance whenever its reliability $R g$ reaches a given threshold level, $\operatorname{Rg}_{\text {inf }}$ (Martinod et al., 2018). Let the working cycles range be 
expressed as $A_{j}=\omega_{A}-\omega_{o}$ such that $\operatorname{Rg}\left(\omega_{o}\right)$ is the reliability level of the last preventive maintenance denoted as $R g_{o}$, and $\exists \omega_{A} \in \omega: R g\left(\omega_{A}\right)=R g_{\text {inf }} . \omega_{A}$ represents the quantity of working cycles in which the system reaches the reliability threshold level $R g_{\text {inf }}$ (see Figure 3(d)). Therefore, $A$ covers the working cycles executed by the system in response to deterioration between preventive maintenances, and the period between maintenances can be expressed as $A_{j}=R g^{-1}\left(R g_{i n f}\right)-R g^{-1}\left(R g_{o}\right)$, where $\operatorname{Rg}^{-1}(\cdot)$ expresses the inverse function of the global reliability. The cost of the age-based maintenance policy is expressed as follows:

$$
\Gamma a=\sum_{j} A_{j}^{-1} C i_{j}
$$

Section 4.3 will develop an application example of the maintenance parameters behaviour regarding types of preventive maintenance policies: periodic bock-type and age-based.

\subsection{Formulation of the joint service-maintenance problem}

This work introduces a stochastic optimisation model in order to simultaneously prove a cost-efficient service and maintenance plan. The decision variables are the service rate, $q v_{n}$ and $s v_{n}$ (adopted for each period) and the periodicity of the maintenance actions, $T_{j}$ and $A_{j}$ (corrective and preventive). The optimal service plan is obtained by minimising the expected penalty cost for passengers waiting time and the cost of maintenance activities. From that point, the proposed model merges the service policy and the maintenance policy. The maintenance cost increases as a service level increases (i.e. decreasing the cost of waiting time). Formally, the problem is solved through a cost-based model made up of waiting cost, $\Gamma w g$ (Equation (12)), corrective maintenance cost, $\Gamma c$ (Equation (13)) and preventive maintenance cost, $\Gamma p$ (Equation (19)) and $\Gamma a$ (Equation (20)), as follows:

$$
\omega_{j}^{\min } C:\left\{\begin{array}{l}
C w \sum_{n} W g_{n}+\sum_{j} C c_{j} \varphi_{j}+\sum_{j} T_{j} C i_{j} ; \text { if periodic block maintenance } \\
C w \sum_{n} W g_{n}+\sum_{j} C c_{j} \varphi_{j}+\sum_{j} A_{j}^{-1} C i_{j} ; \text { if = }
\end{array}\right.
$$

subject to the following constraints:

$$
\begin{gathered}
0 \leqslant g_{k, i, n} \leqslant c v, \quad \forall k, i, n, \\
0 \leqslant \mu_{i, n} \leqslant \min \left(L q_{i, n}, g_{k, i, n}\right), \quad \forall i, n, \\
0 \leqslant \sigma_{k, n} \leqslant c v-g_{k, i, n}, \quad \forall k, n, \\
s v_{i n f} \leqslant s v_{n} \leqslant s v_{s u p}, \quad \forall n, \\
q v_{i n f} \leqslant q v_{n} \leqslant q v_{s u p}, \quad \forall n, \\
R g_{\text {inf }} \leqslant R g \leqslant 1, \\
0 \leqslant W g_{n} \leqslant W g_{s u p},
\end{gathered}
$$


where:

$$
\begin{gathered}
0 \leqslant \sum_{i, n} \lambda_{i, n} \leqslant c v \sum_{n} s v_{n} q v_{n}, \\
\sum_{i, n} \lambda_{i, n}=\sum_{k, n} \sigma_{k, n},
\end{gathered}
$$

Urban ropeway transport systems

- Equation (21a) highlights that the available places of a vehicle, $g_{k, i, n}$, must be less or equal to the vehicle's capacity, $c v$.

- Equation (21b) means the quantity of passengers boarding the vehicle, $\mu_{i, n}$, must be less or equal that the quantity of passengers waiting in the queue, $L q$; but besides, $\mu_{i, n}$ must be less or equal that the available places of the vehicle, $g_{k, i, n}$.

- Equation (21c) expresses that the quantity of passengers disembarking from the vehicle, $\sigma_{k, n}$, must be less or equal than the quantity of the passengers travelling inside the vehicle, $c v-g_{k, i, n}$.

- Equation (21d) is related to an operating condition; namely, the speed of the vehicles $s v_{n}$ which is limited by a range $\left[s v_{i n f}, s v_{s u p}\right]$.

- Equation (21e) refers to another operating condition; namely, that the system must have a range of vehicles in active service (density of vehicles) $\left[q v_{i n f}, q v_{s u p}\right]$.

- Equation (21f) is related to the maintenance policy, where $R g_{\text {inf }}$ is the lower limit of global reliability of the system.

- Equation (21g) is related to other service policy, where $W g_{s u p}$ is the upper limit of global waiting time in the queue.

- Equation (21h) implies that the capacity of the transport system, $c v \sum_{n} s v_{n} q v_{n}$, must be greater than the total passenger demand for a given time horizon in the transport system, $\sum_{i, n} \lambda_{i, n}$; otherwise, the system is overloaded.

- Equation (21i) indicates that the quantity of passengers disembarking from all vehicles on the time horizon $\sum_{k, n} \sigma_{k, n}$ must be equal to the quantity of users that arrive on the platforms, $\sum_{i, n} \lambda_{i, n}$. It means that with the close of a period of service time at the end of a full working day, all passengers are served and no one remains in the system. In other words, when the system is closed after a working day, the system is empty.

A model of the ropeway transport has been developed in a virtual environment using a programming language, which allows investigating the effects of a wide range of possible conditions and parameters variation. The results obtained from the model provide accurate predictions of the behaviour of the system and its interaction with the decision variables, obtained using acceptable computing resources: the algorithm was developed in a high-level programming language - MATLAB R2018a; and the data were run on a processor Intel Core 17 CPU@2.93 GHz $3.07 \mathrm{GHz}, 64$ bits, 16 GB RAM. A ropeway transport system has been defined (see Table AI). A sensitivity model analysis is executed by mean of 50 sets of test, every test covers 500 events. The input data are $\lambda_{i, n}$ (a set to each platform) which are defined as a set of variables with stochastic Poisson distribution (see Figure 4).

Figure A1 shows every single mean waiting time $W g_{n}$, which represents the estimator used to describe the system behaviour over the discrete-time; therefore, a relationship can be established between a measure of central tendency such as the average values, mean $\left(W g_{n}\right)$, and the measure of dispersion such as the deviation standard, $\operatorname{std}\left(W g_{n}\right)$, to quantify the sensitivity of the model regarding the events. The ratio between mean $\left(W g_{n}\right)$ and $\operatorname{std}\left(W g_{n}\right)$ to each platform is $\{0.007,0.065,0.011,0.098\}$ per cent, which represents an acceptable deviation level for the scope of this work. 


\section{IJQRM}

Figure 4.

Poisson distribution of arriving users to the platforms, $\lambda_{i, n}$
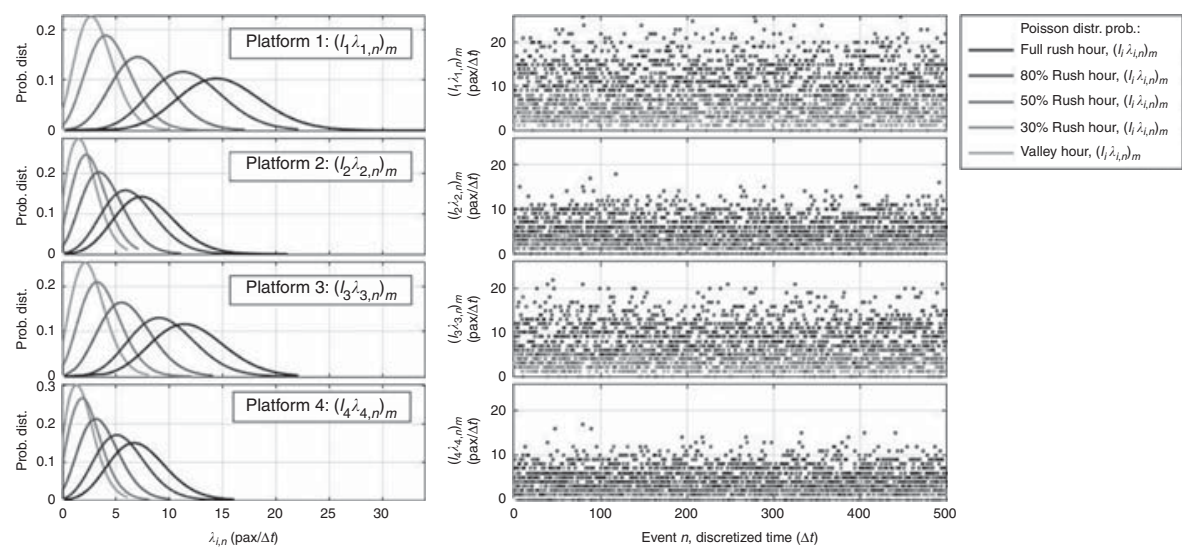

The model is subjected to a convergence analysis to reach a stable value. Figure A2 shows the results of the mean waiting time in the queue to each platform, a lower value of 3 per cent variation represents an acceptable level of deviation from this study. Therefore, in order to fulfil the requirement a total of 18 simulations are necessary.

\section{Case study: urban aerial ropeway system}

This section provides an application example to expose the obtained numerical results. According to the general operational characteristics of ropeway transport systems, two types of aerial ropeways are identified (Mizuma, 2004; Alshalalfah et al., 2013):

(1) Aerial tramway - téléphérique - in this system, two large vehicles (cabins) are permanently attached to each leg of the pulling cable which alternatively turns in one direction. The vehicles stop when they reach the station (see Figure 5(a)). This feature allows vehicle speed and cable velocity to remain the same throughout the journey. In addition, two operational aerial tramway designs are available: an aerial tramway -reversible ropeway system consists of two vehicles suspended from cables, situated at opposite ends of the cable loops - when one is ascending, the other is descending, and they pass each other midway on the cable span; in a dualhaul aerial tramway system, there are two reversible vehicles that run on parallel tracks. There are two guide ropes and a haul rope loop per vehicle, which allow for single-vehicle operation when demand warrants.

(2) Gondola - télécabine - this system has a pulling cable revolving constantly in one direction; the vehicles (gondolas) are attached and detached when entering and travelling through a platform (see Figure 5(b)). This feature allows the vehicles to be set at regularly spaced close intervals with the cable continuously circulating with the vehicles. The vehicles detach from the hauling rope at the platforms, decelerated and carried at a very low speed through an embarking/disembarking area and finally accelerating upon reattachment to the haulage rope for high speed travel on the line between stations. There are three gondola designs: the monocable detachable gondola, with vehicles that are suspended from a moving loop of steel cable; the bi-cable detachable gondola, which uses reversible ropeway technology, but the system is detachable, which allows the system to have a high capacity and a detachable circulating systems; and tri-cable detachable gondola $3 \mathrm{~S}$ - combines features of both gondola and reversible ropeway systems and detachable gondolas. 
(a)

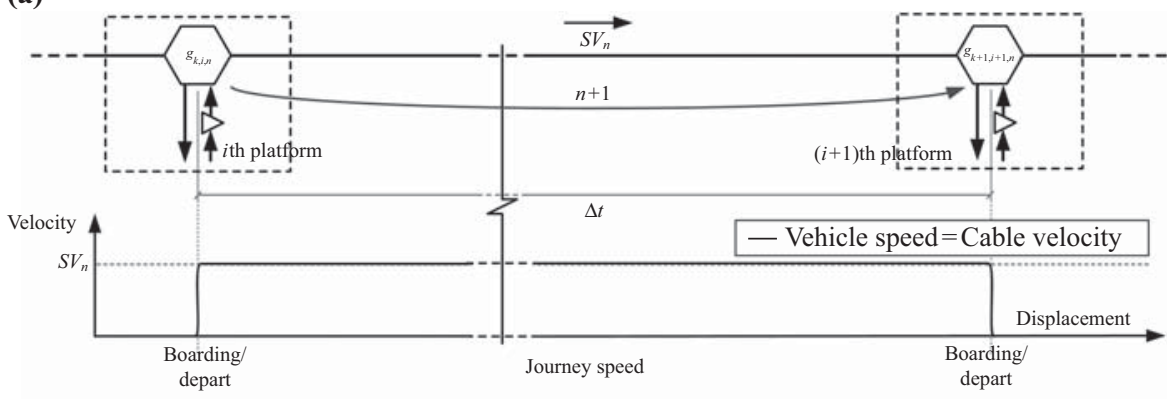

Urban ropeway transport systems

(b)

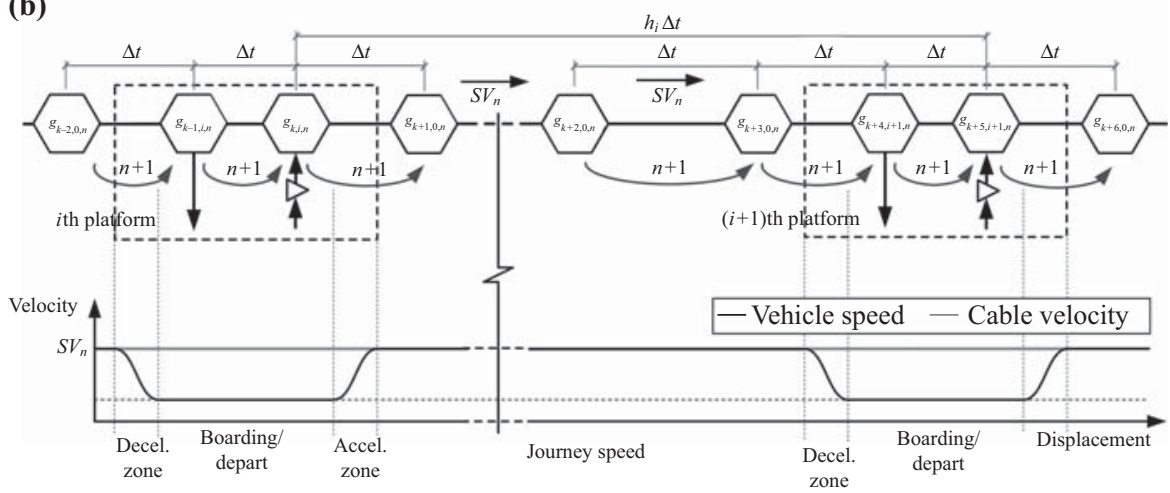

Notes: (a) Aerial tramway (tèlèphèrique) fixed cabins; (b) gondola (tèlècabine) with a detachable release clamp

Our case study is concerned with a fleet supporting an urban mass-transport system, which operates in the city of Medellin (Co); it has been manufactured by Poma (Fra.) since 2004, providing continuous service 360 day a year, 7 days a week, 20 hours a day. The object of study is a gondola-type aerial cable system running on a continuous cycle, see Figure 5(b), mono-cable (simple ring) with a detachable release clamp device (Martinod et al., 2015). Table AI shows the overall technical characteristics of the object of study. This was the first time that an aerial cable was used for urban purpose, completely different from a tourist purpose. It is similar in design and construction to those used for tourist passenger transports in winter regions (e.g. Daemyung, Korea; La Clusaz, France; Donovaly, Slovakia) (Estepa et al., 2014), but it does not share the tourist purpose of these other examples (Mizuma, 2004). Therefore, the transport system in question is required at high levels of service demand that have not been supported by similar systems, causing highly elevated wear rates (Hoffmann, 2006); it will be hence the aerial cable transportation system with highest level of demand, in terms of wear hours of components and service (Martinod et al., 2015).

\subsection{Service parameters behaviour}

A set of tests has been developed in which the decision variables $\left(s v_{n}, q v_{n}\right)$ were considered; thus, a set of combinatory tests was performed based on the ranges of operation of the ropeway system, $q v_{n}=\{50, \ldots, 66\}(\mathrm{veh})$ and $s v_{n}=\{1.5, \ldots, 5.5\}(\mathrm{m} / \mathrm{s})$. With each combination run, the quantity of simulations was defined by the convergence analysis to check the stability of results (Section 3.3). 
IJQRM

Table I.

Passengers' demand conditions of the transport ropeway system

The weighted mean of users who arrive on terminal platforms $\left(\lambda_{1, n}, \lambda_{3, n}\right)$ and the halfwayplatforms $\left(\lambda_{2, n}, \lambda_{4, n}\right)$ reflects the different levels of demand at these locations (e.g. the typical demand service of the terminal platforms are higher than the halfway-platforms). The relationship between the different levels of the passenger demand can be expressed as $l_{i} \lambda_{i, n}$ where $l_{i}$ is the proportional coefficient between platforms; as such, $l_{1} \lambda_{1, n}=l_{2} \lambda_{2, n}=l_{3} \lambda_{3}$, ${ }_{n}=l_{4} \lambda_{4, n}$. In the proposed example, the relationship between the passenger demand at each platform can be written as $\lambda_{1, n}=1.87 \lambda_{2, n}=1.25 \lambda_{3, n}=2.13 \lambda_{4, n}$. In addition, the tests are structured by the conditions of user demand from rush hour to off-peak periods; see Figure 2 (a). A set of five demand conditions are established $\left(l_{i} \lambda_{i, n}\right)_{m}$ with $m=\{1, \ldots, 5\}$ where $\left(l_{i} \lambda_{\mathrm{i}, n}\right)_{1}$ represents the demand conditions of full rush hour, and $\left(l_{i} \lambda_{i, n}\right)_{5}$ represents the demand conditions of off-peak periods; thus, a total of 8.917 tests were executed. Table I shows the $m$ th Poisson parameter of $\left(l_{i} \lambda_{i, n}\right)_{m}$ to the $i$ th platform (see Figure 6).

The results of these tests are synthesised in Figure 7. An initial analysis was carried out to identify the combination of the values $s v_{n}$ and $q v_{n}$ that must be provided by the transport system to reach a service policy without incurring passenger waiting time; i.e., $W g_{n}=0$. Figure 7(a) shows the boundary values of $s v_{n}$ and $q v_{n}$ in each demand condition. If the manager chooses a set of values equal to or higher than the boundary, the users can board the vehicle without waiting in a queue. A second analysis is focused on assessing the values of $s v_{n}$ and $q v_{n}$ at which the transport system can offer a service with an acceptable waiting time of passengers defined by the service policy, i.e. $W g_{n} \leqslant W g_{s u p}$. Figure 7(b) shows these boundary values. If the manager chooses a set of values $s v_{n}$ and $q v_{n}$ equal to or higher than the boundary, the users face a shorter waiting time than the waiting limit, $W g_{s u p}$. A third analysis is the quantification of $\Gamma w g$ according each user demand conditions $\left(\lambda_{i, n}\right)_{m}$, see Figure $7(\mathrm{c})$.

\begin{tabular}{lcccccc}
\hline & \multicolumn{6}{c}{ Rush hour } \\
& & Full & $80 \%$ & $50 \%$ & $30 \%$ & Valley hour \\
& & $m=1$ & $m=2$ & $m=3$ & $m=4$ & $m=5$ \\
\hline Platform 1 & $\left(l_{1} \lambda_{1, n}\right)_{m}$ & 15.0 & 12.0 & 7.5 & 4.5 & 3.0 \\
Platform 2 & $\left(l_{2} \lambda_{2, n}\right)_{m}$ & 8.0 & 6.4 & 4.0 & 2.4 & 1.6 \\
Platform 3 & $\left(l_{3} \lambda_{3, n}\right)_{m}$ & 12.0 & 9.6 & 6.0 & 3.6 & 2.4 \\
Platform 4 & $\left(l_{4} \lambda_{4, n}\right)_{m}$ & 7.0 & 5.6 & 3.5 & 2.1 & 1.4 \\
\end{tabular}

(a)

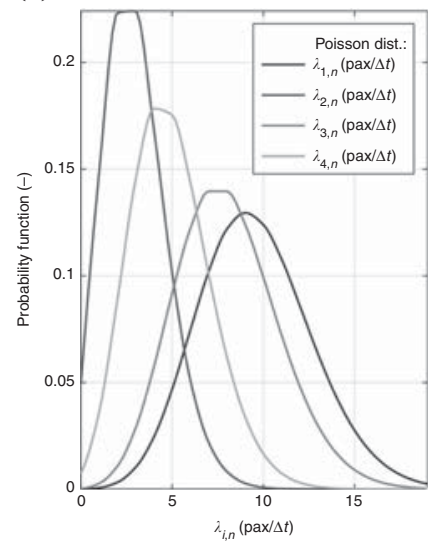

(b)

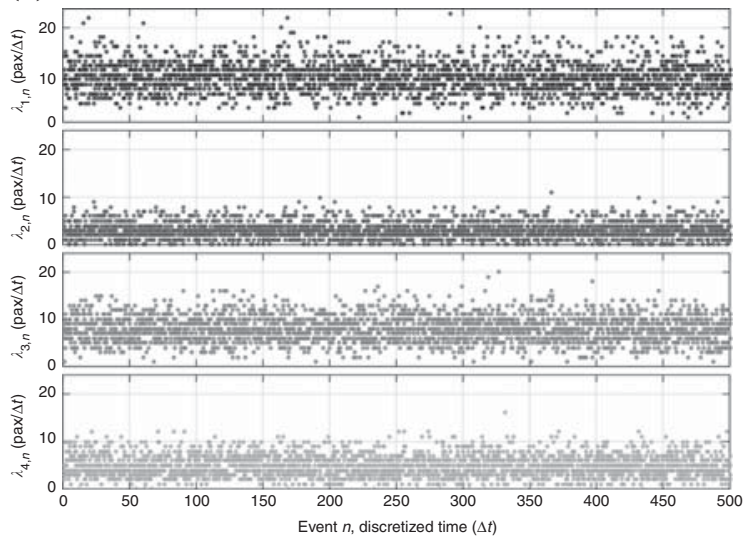

Figure 6.

Data set of users arrival conditions, $\left(l_{i} \lambda_{i, n}\right)_{m}(\operatorname{pax} / \Delta t)$

Notes: (a) Probability functions of users arrival; (b) dataset of users arrival 
(a)
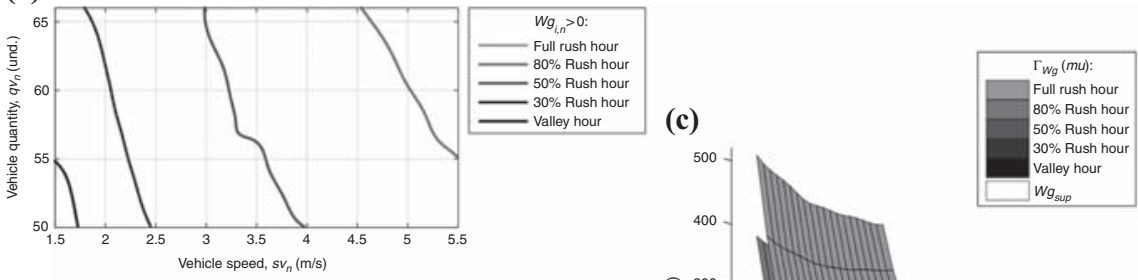

Urban ropeway transport systems

(b)

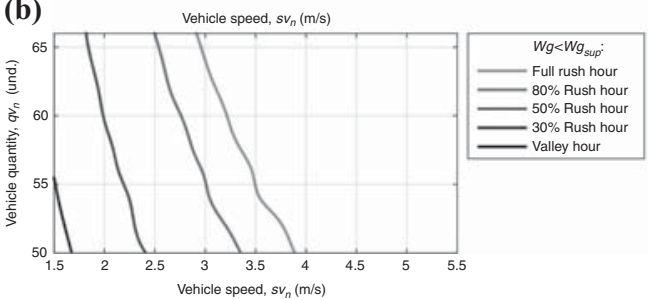

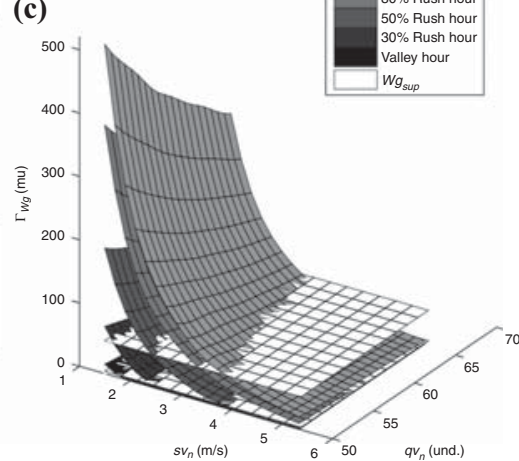

Notes: (a) Waiting time level, $W g<0$; (b) waiting time exceeds the waiting level, $W g<W g_{\text {sup }}$; (c) waiting time cost, $\Gamma_{W g}(\mathrm{mu})$

\subsection{Maintenance parameters behaviour}

The example is focused on the maintenance conditions of two sets of critical components for the exploitation of ropeway transport: the conveyor-track system, and traction system.

The conveyor-track system has the ability to decelerate/accelerate the vehicles around each platform; there is one independent system per platform. The conveyor-track system is considered one of the structural components (according to the Section 2.2). The ropeway system requires that every conveyor-track works, or else the system must stop until the failure is fixed, this affecting the service policy; thus, the sets of conveyor-track systems have a series configuration on the ropeway transport, with a set of reliability functions expressed as $\left\{R_{1}, R_{2}, R_{3}, R_{4}\right\}$.

The traction system is composed by three independent and redundant systems $\left\{R_{5}, R_{6}\right.$, $R_{7}$ \} (see Figure 8). There are two sets of electric motors, with each motor joined to a different gearbox. The ropeway system requires just one working motor-gearbox, and the second, standby motor-gearbox is available for maintenance actions. The third redundant traction system is a set of engine-gearbox; this traction system works in the case the electrical network undergoes a cut off. Thus, the sets of traction systems have a parallel configuration on the ropeway transport.

Following the example, the set of reliability function is $\left\{R_{1}, \ldots, R_{J}\right\}$ with $J=7$, and the global reliability expression is $R_{g}=\prod_{j=1}^{J-3} R_{j} \cdot\left(1-\prod_{j=5}^{J}\left(1-R_{j}\right)\right)$. A previous study (Trujillo, 2013) developed an evaluation and analysis focused on components of a ropeway system based on reliability, maintainability and availability. That study measured the fault probability distribution of the detachable grips, and its reliability probability. The author made a Kosmogorov-Smirnov test and found that the distribution of the faults belongs to Weibull distributions.

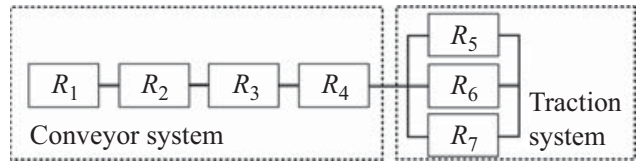

Figure 8.

Components configuration on the ropeway system
Service parameters behaviour, $W g(\Delta t)$ and $\Gamma w g(\mathrm{mu})$ 
The example considers all analysed components, $j=\{1, \ldots, J\}$ belonging to the same type of components (in this case, the components belong to the structural elements in the system), the same maintenance policy is applied to the same type of the components. An analysis of the failure probability progress on the transport system is made. Deterioration of the system is computed in three stages: first, the functions $f_{j}, F_{j}$ and $R_{g}$ are calculated to obtain the progressive degradation of the system according to typical operation conditions. Considering just the corrective maintenance actions, it means a reactive maintenance policy is applied, without preventive maintenance actions, see Figure 9(a). Second, the effect of the preventive imperfect maintenance action to each period of time is calculated. Third, the degradation system is found by the superposition principle, to get the mixed effect due to the corrective and preventive maintenance actions on the system (see Figure 9(b)). Two scenarios are considered for application example:

(1) Maintenance cost calculated according to periodic block-type preventive maintenance. This is the current maintenance policy applied by the maintenance managers of ropeways systems and it is the traditional maintenance policy established by the international regulation. The decision variables $\left(T_{j}, s v_{n}, q v_{n}\right)$ have been considered as a combinatorial tests based on the range $T_{j}=\{3, \ldots, 12\}$ (maint./year) and the working cycles $\omega\left(s v_{n}, q v_{n}\right)=\{1.18 \mathrm{E} 4, \ldots, 4.56 \mathrm{E} 4\}$ (cycles). Each combination was run and the quantity of simulations was governed by the convergence analysis to check the stability of results. Figure 10(a) shows a synthesis of the results. The cost of the periodic block-type preventive maintenance does not rely on the degradation of the components, but it is directly proportional to its periodicity, $T_{j}$. The cost of the corrective maintenance increases with the degradation of the components, but decreases with the periodicity of the periodic block-type preventive maintenance.

(2) Age-based preventive maintenance. This scenario can be used to quantify the effectiveness of the applied current maintenance policy used by the maintenance management. Figure 10(b) shows a synthesis of the results. The cost of the age-based preventive maintenance depends on the degradation of the components. As such, quantity of maintenance actions is in function of $R g$. Note that the quantity of preventative maintenances corresponds to seven maintenance actions per year, the cost of the corrective maintenance changes of tendency; i.e., the cost behaviour of the

(a)

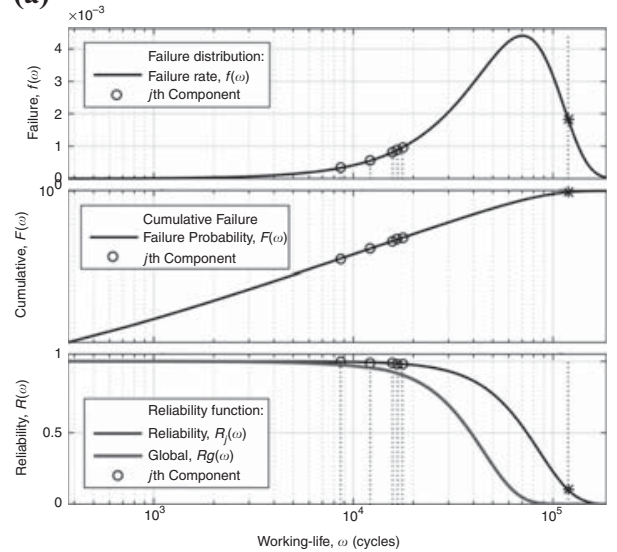

(b)

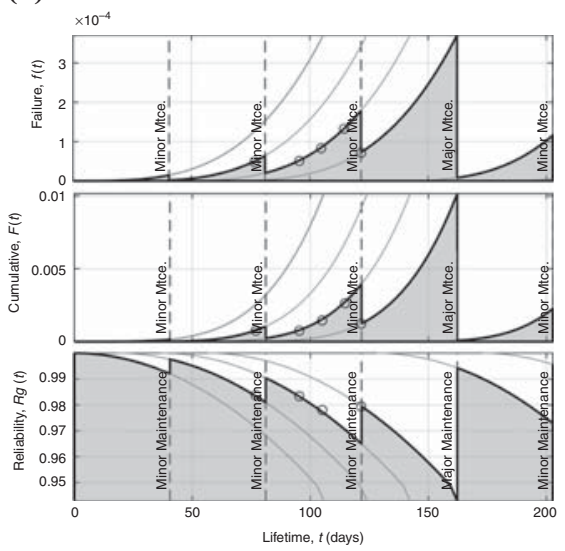

Figure 9.

Failure probability progress of the system

Notes: (a) Failure probability at frequency domain; (b) effects of preventive maintenance actions 
(a)

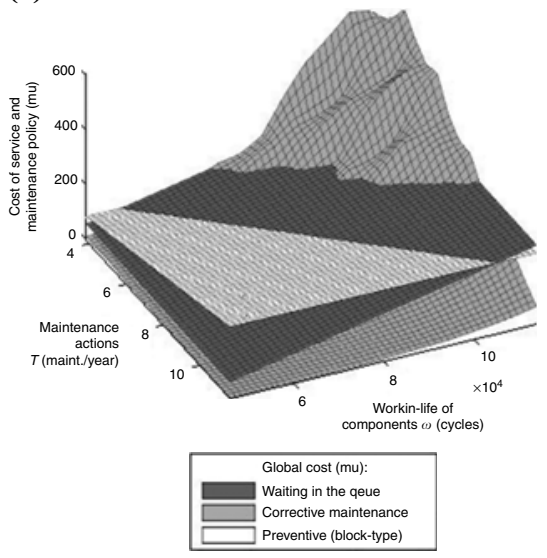

(c)

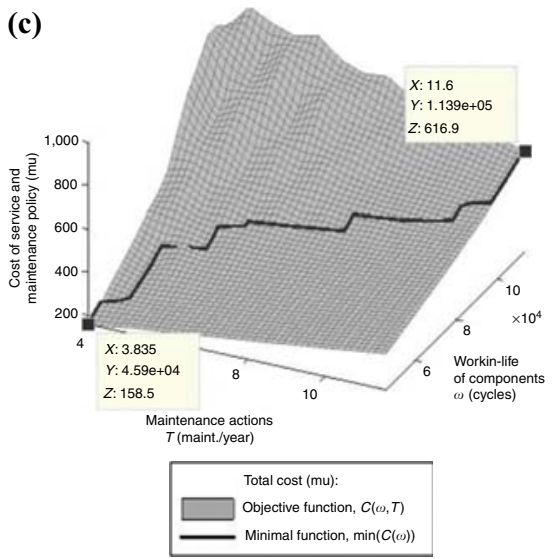

(b)

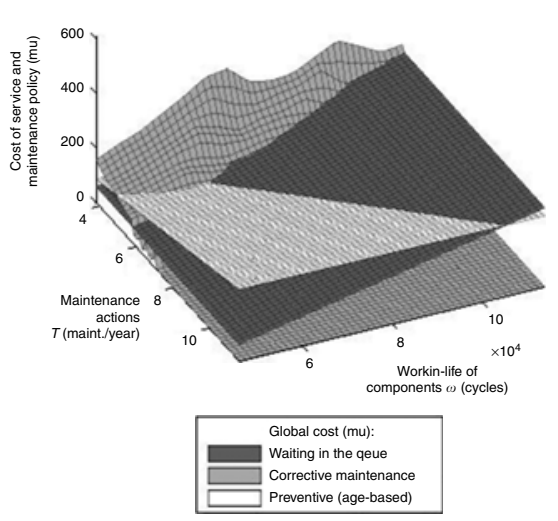

(d)

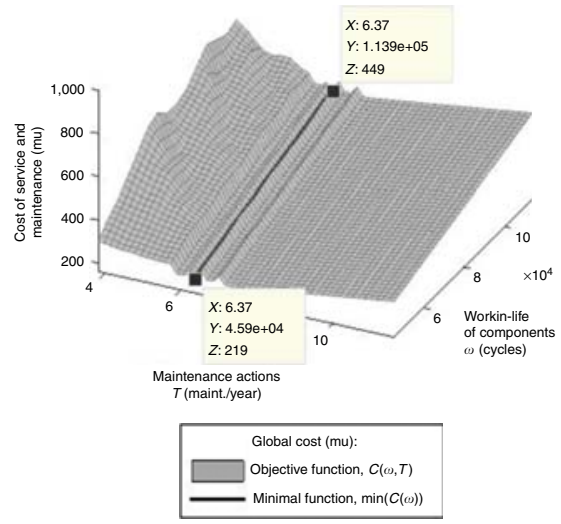

(e)

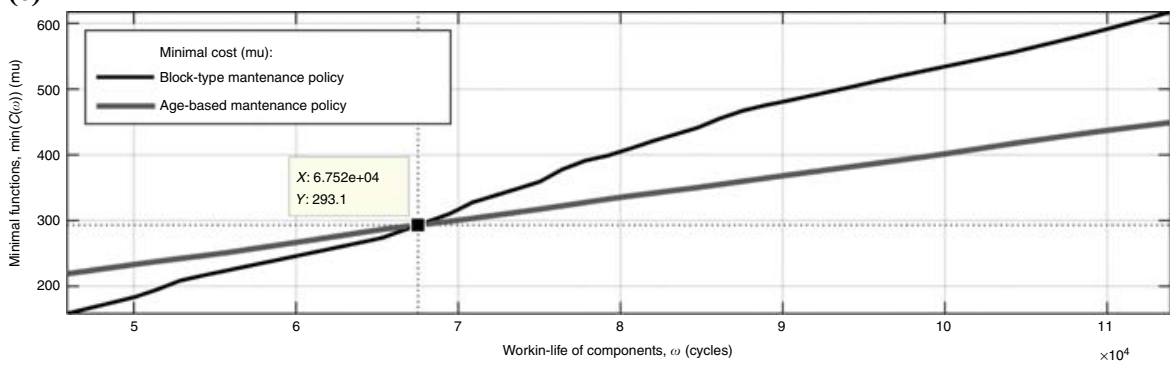

Notes: (a) Cost of service and periodic block-type maint. policy; (b) cost of service and age-based maint. policy; (c) objective fn. with a periodic block-type maint. policy; (d) objective fn. with an age-based maint. policy; (e) minimal functions of different maintenance policies

Figure 10.

Cost of service and maintenance policies

corrective maintenance for the age-based preventive maintenance can be classified in two performances: the value of the corrective maintenance cost decreases until a defined quantity of preventive maintenances, and after the defined quantity of preventive maintenances, the value of the corrective maintenance cost remains almost constant. 


\subsection{Cost of service and maintenance policies}

By using Equation (21), which relates the cost of the service and maintenance policies, it is possible to get two independent objective functions $C\left(T_{j}, \omega\right)$ : first, an objective function regarding to the periodic block-type maintenance policy (see Figure 10(c)), and second, an objective function regarding to the age-based maintenance policy (see Figure 10(d)).

An analysis of $\min \left(C\left(T_{j}, \omega\right)\right)$ belonging to the periodic block-type maintenance policy shows that the lowest cost is obtained through quarterly preventive maintenance actions for a working-life of 4.59E4 (cycles). However, once the working-life reaches a value of 1.139E5 (cycles), the lowest cost is achieved with a monthly preventive maintenance action. The function $\min \left(C\left(T_{j}, \omega\right)\right)$ belongs to the age-based maintenance policy. It indicates that the periodicity of the preventive actions has a constant value over the working-life of the system. The lowest cost is gotten with a two-month preventive maintenance action.

Figure 10(e) shows the relationship between the functions $\min \left(C\left(T_{j}, \omega\right)\right)$ in each of the maintenance policies. Note that if the components of the system have a low working-life value, the appropriate policy is the periodic block-type maintenance (the cost of the periodic block-type maintenance is 27.62 per cent lower than the age-based maintenance). However, if the components of the system undergo wear and a decline in performance, due to the high demand on the system, the appropriate policy is the age-based maintenance (the cost of the periodic block-type maintenance is 37.40 per cent higher than the age-based maintenance). Therefore, there is an optimal working-life value for a change in the maintenance policy. This value ensures minimal cost (considering the operational service and the maintenance actions) during the service life of the transport system. The optimal working-life value is calculated as 6.75E4 (cycles).

\section{Conclusions and discussion}

In this study, a mathematical framework is developed to integrate service and maintenance policies in order to solve the queuing problem and the cost of maintenance actions in public transport services. For this purpose, the authors have proposed: a stochastic discrete-event model composed of a set of interrelated queues for the formulation of the service problem using a cost-based mathematical expression; and an imperfect preventive maintenance based on two different maintenance polices (periodic block-type maintenance and age-based maintenance).

In the first stage of the analysis, a mathematical model of the service policy was proposed to determine the values of the operational parameters $\left(s v_{n}, q v_{n}\right)$ in which the transport system offers different levels of service quality: users get the service they need without waiting in a queue; and an acceptable waiting time for passengers, defined on the basis of the service policy. Furthermore, in our analysis, the penalty cost in terms of global waiting time, $\Gamma w g$, was considered as a term of the optimisation model based on cost, $C\left(T_{j}, \omega\right)$. In a later stage of the research, this work developed a stochastic model of maintenance that considers the degradation for a multi-component system with a dependence relationship between the components. Through our analysis, the model cost of maintenance (which includes the corrective and preventive maintenance action) completes $C$ $\left(T_{j}, \omega\right)$. An optimisation model $C\left(T_{j}, \omega\right)$ has been formulated to bring together the service and maintenance policies, making it possible to determine the optimal cost function $\min (C(\omega))$ such that the cost over a long time window of working-life was minimised.

This work developed an optimisation model that integrates the service and operations policies with the maintenance policy of a transport system. We show that neither periodic block-type maintenance nor an age-based maintenance is necessarily the best maintenance strategy over a long system lifecycle. The optimal strategy must consider both policies; at the beginning of the working-life, applying a periodic block-type is likely the most advantageous, but as the components of the system undergo age and deteriorate, an agebased maintenance policy is likely the preferable option. 
Currently, maintenance managers of transport systems apply a single maintenance policy during the working-life cycle. This paper provides strong support to the idea that an optimal maintenance policy is a mixed policy. Therefore, current maintenance strategies should be reconsidered in order to improve service and the maintenance activities.

Future research will focus on the four major aspects. From the perspective of passenger demand, transport systems are not independent, they are interconnected and intermodal. Further analysis of service delivery and the passengers' facilitation process can be undertaken with regard to a ropeway system's connection to an intermodal transport network. This calls for a more robust algorithm to speed up the data processing for solving larger-scale problems. Second, it is possible to propose other study, in which broaden different relationships of the penalty cost for the global waiting time - polynomial functions, hyperbolic functions, exponential function, etc. - where an analysis of the system characteristics and its implications are considered. The present work has only considered a linear function for this relationship and for the implications for the service policy. Third, it is perceived that urban transport undergoes a remarkable intensity of passengers flow in one direction over defined periods - people go to work, students go to schools, etc. - generating a strong asymmetric demand of passengers over the ropeway system. This urban transport characteristic can be further embedded into the formulated model. Fourth, this work provides an analysis which considers the user requirements and the company profit. Building on that, it is possible to propose a further analysis that includes the social cost and the environmental cost; thus, an approximation of sustainability model can be proposed. Finally, this work assumed that all analysed components belong to the same type of elements, and therefore the same maintenance policy is applied to the components, and in addition the preventive maintenance actions are performed on all components at the same time. As such, it would be possible in future to develop a maintenance model which considers components affected by multiple types of independent degradation processes.

\section{References}

Alardhi, M., Hannam, R.G. and Labib, A.W. (2007), "Preventive maintenance scheduling for multicogeneration plants with production constraints", Journal of Quality in Maintenance Engineering, Vol. 13 No. 3, pp. 276-292.

Alaswad, S., Cassady, R., Pohl, E. and Li, X. (2017), "A model of system limiting availability under imperfect maintenance”, International Journal of Quality \& Reliability Management, Vol. 23 No. 4, pp. 415-436.

Alshalalfah, B., Shalaby, A. and Dale, S. (2014), "Experiences with aerial ropeway transportation systems in the urban environment", Journal of Urban Planning and Development, Vol. 140 No. 1, pp. 1-12.

Q7 Alshalalfah, B., Shalaby, A., Dale, S. and Othman, F.M.Y. (2012), "Aerial ropeway transportation systems in the urban environment: state of the art", Journal of Transportation Engineering, Vol. 138, pp. 253-262.

Alshalalfah, B., Shalaby, A., Dale, S. and Othman, F.M.Y. (2013), "Improvements and innovations in aerial ropeway transportation technologies: observations from recent implementations", Journal of Transportation Engineering, Vol. 139 No. 8, pp. 814-821.

Amirgholy, M. and Gonzales, E.J. (2016), "Demand responsive transit systems with time-dependent demand: user equilibrium, system optimum, and management strategy", Transportation Research: Part B, Vol. 92, pp. 234-252.

Barrena, E., Canca, D., Coelho, L.C. and Laporte, G. (2014a), "Single-line rail transit timetabling under dynamic passenger demand", Transportation Research: Part B, Vol. 70, pp. 134-150.

Barrena, E., Canca, D., Coelho, L.C. and Laporte, G. (2014b), "Exact formulations and algorithm for the train scheduling problem with dynamic demand”, Computers \& Operations Research, Vol. 44. pp. 66-74. 
Bocarejo, J.P., Portilla, I.J., Velásquez, J.M., Cruz, M.N., Peña, A. and Oviedo, D.R. (2014), “An innovative transit system and its impact on low income users: the case of the metrocable in Medellin", Journal of Transport Geography, Vol. 39. pp. 49-61.

BS/EN-1709 (2004), "Safety requirements for cableways for cableway installations designed to carry persons. Precommissioning inspection, maintenance and operational inspection and checks", Committee MCE/20, 24.

Ceder, A. (2007), Public Transit Planning and Operation: Theory, Modeling and Practice, Elsevier Publisher, pp. 320-342.

Ceder, A., Chowdhury, S.J., Taghipouran, N. and Olsen, J. (2013), "Modelling public-transport users' behaviour at connection point", Transport Policy, Vol. 27, pp. 112-122.

Cholasuke, C., Bhardwa, R. and Antong, J. (2004), "The status of maintenance management in UK manufacturing organisations: results from a pilot survey", Journal of Quality in Maintenance Engineering, Vol. 10 No. 1, pp. 5-15.

Dalla-Chiara, B. (2010), "Guidelines for the engineering and design of rope transport systems", Department of Transport Engineering, Politecnico di Torino, pp. 6-17.

Directive 2000/9/EC (2000), "Relating to cableway installations designed to carry persons. The European Parliament and of the Council of European Union”, Official Journal of the European Communities, pp. 21-48.

Estepa, D., Martinod, R.M., Paris, C.E., Pineda, F.A., Restrepo, J.L., Castañeda, L.F. and Mejía, G.A. (2014), "Operating conditions effect over the coupling strength for urban aerial ropeways", Transport Problems, Vol. 9 No. 3, pp. 5-14.

Fraser, K., Hvolby, H.H. and Tseng, B. (2015), "Maintenance management models: a study of the published literature to identify empirical evidence. A greater practical focus is needed", International Journal of Quality \& Reliability Management, Vol. 32 No. 6, pp. 635-664.

Fraser, K., Hvolby, H.H. and Watanabe, C. (2011), "A review of the three most popular maintenance systems: how well is the energy sector represented?", International Journal of Global Energy Issues, Vol. 35 No. 4, pp. 287-309.

Gillen, D. and Hasheminia, H. (2013), "Estimating the demand responses for different sizes of air passenger groups", Transportation Research: Part B, Vol. 49, pp. 24-38.

Hajej, Z., Bistorin, O. and Rezg, N. (2012), "Maintenance/production plan optimization taking into account the availability and degradation of manufacturing system", Proceedings of the 14th IFAC Symposium, IFAC Proceedings, Bucharest, Vol. 45 No. 6, pp. 963-967.

Hajej, Z., Dellagi, S. and Rezg, N. (2014), "Joint optimisation of maintenance and production policies with subcontracting and product returns", Journal of Intelligent Manufacturing, Vol. 25. pp. 589-602.

Hajej, Z., Turki, S. and Rezg, N. (2014), “A jointly optimization of production, delivery and maintenance planning for multi-warehouse/muli-delivery problem", Probabilistic Safety Assessment and Management. Honolulu, HI.

Hajej, Z., Turki, S. and Rezg, N. (2015), "Modelling and analysis for sequentially optimizing production, maintenance and delivery activities taking into account product returns", International Journal of Production Research, Vol. 53 No. 15, pp. 4694-4719.

Hall, R.W. (2003), “Transportation queueing”, Handbook of Transportation Science, 2nd ed., Kluwer Academic Publisher, pp. 113-150.

Heinrichs, D. and Bernet, J.S. (2014), "Public transport and accessibility in informal settlements: aerial cable cars in Medellín, Colombia", Transportation Research Procedia, Vol. 4 pp. 55-67.

Hoffmann, K. (2006), "Recent developments in cable-drawn urban transport systems", FME Transactions, Vol. 34 No. 4, pp. 205-212.

Horn, M.E.T. (2002), "Multi-modal and demand-responsive passenger transport systems: a modelling framework with embedded control systems", Transportation Research: Part A, Vol. 36 No. 2, pp. 167-188. 
Ibarra-Rojas, O.J., Delgado, F., Giesen, R. and Muñoz, J.C. (2015), "Planning, operation, and control of bus transport systems: a literature review”, Transportation Research: Part B, Vol. 77 pp. 38-75.

Ison, S. and Sagaris, L. (2016), "Workshop 4 report: developing inter-modal transport systems", Research in Transportation Economics, Vol. 59, pp. 175-178.

Jenelius, E. (2018), "Public transport experienced service reliability: integrating travel time and travel conditions", Transportation Research: Part A, Vol. 117 pp. 275-291.

Jones, W.B., Cassady, C.R. and Bowden, R.O. (2000), "Developing a standard definition of intermodal transportation”, Transportation Law Journal, Vol. 27, pp. 345-352.

Kahraman, A. and Gosavi, A. (2011), "On the distribution of the number stranded in bulk-arrival, bulk-service queues of the M/G/1 form”, European Journal of Operational Research, Vol. 212 No. 2, pp. 352-360.

Khatab, A., Ait-Kadi, D. and Rezg, N. (2013), "Availability optimisation for stochastic degrading systems under imperfect preventive maintenance", International Journal of Production Research, Vol. 52 No. 14, pp. 4132-4141.

Knezevic, A., Vasov, L., Vlacic, S. and Kostic, C. (2017), "Imperfect maintenance model for estimating aircraft fleet availability", Aircraft Engineering and Aerospace Technology, Vol. 89 No. 2, pp. 338-346.

Lee, Y.J. and Vuchic, V.R. (2005), "Transit network design with variable demand", Journal of Transportation Engineering, Vol. 131 No. 1, pp. 1-10.

Li, Z.C. and Sheng, D. (2016), "Forecasting passenger travel demand for air and high-speed rail integration service: a case study of Beijing-Guangzhou corridor, China", Transportation Research: Part A, Vol. 94, pp. 397-410.

Martinod, R.M., Bistorin, O., Castañeda, L.F. and Rezg, N. (2018), "Maintenance policy optimisation for multi-component systems considering degradation of components and imperfect maintenance actions", Computers \& Industrial Engineering, Vol. 124 pp. 100-112.

Martinod, R.M., Estepa, D., Paris, C.E., Trujillo, A., Pineda, F.A., Castañeda, L.F. and Restrepo, J.L. (2015), "Journey safety assessment to urban aerial ropeways transport systems based on continuous inspection during operation”, Journal of Transportation Safety \& Security, Vol. 7. pp. 279-290.

May, A.D. and Keller, H.E.M. (1967), “A deterministic queueing model”, Transportation Research, Vol. 1 No. 2, pp. 117-128.

Mizuma, T. (2004), "Recent urban transport technologies and assessments", Japanese Railway Engineering, Vol. 44 No. 1, pp. 5-10.

Nesheli, M.M., Ceder, A. and Liu, T. (2015), "A robust, tactic-based, real-time framework for public-transport transfer synchronization”, Transportation Research Procedia, Vol. $9_{k}$ pp. 246-268.

Newell, G.F. (1977), "Unstable Brownian motion of a bus trip", Statistical Mechanics and Statistical Methods in Theory and Applications, Plenum Press Publisher, pp. 645-667.

Niu, H. and Zhou, X. (2013), "Optimizing urban rail timetable under time-dependent demand and oversaturated conditions", Transportation Research: Part C, Vol. 36 pp. 212-230.

Parbo, J., Nielsen, O.A. and Prato, C.G. (2014), "User perspectives in public transport timetable optimization”, Transportation Research: Part C, Vol. 48, pp. 269-284.

Pham, H. and Wang, W. (1996), "Imperfect maintenance", European Journal of Operational Research, Vol. 94 pp. $425-438$.

Pitsiava-Latinopoulou, M. and Iordanopoulos, P. (2012), "Intermodal passengers terminals: design standards for better level of service", Procedia - Social and Behavioral Sciences, Vol. 48, pp. 3297-3306.

Reichenbach, M. and Puhe, M. (2018), "Flying high in urban ropeways? A socio-technical analysis of drivers and obstacles for urban ropeway systems in Germany", Transportation Research Part D, Vol. $61_{k}$ pp. 339-355. 
Sever, D. (2002), "Some new methods to assure harmonisation of sustainable development of mountain resorts ropeway", Promet, Vol. 14 No. 5, pp. 213-220.

Shang, P., Li, R. and Yang, L. (2016), "Optimization of urban single-line metro timetable for total passenger travel time under dynamic passenger demand”, Procedia Engineering, Vol. 137. pp. 151-160.

Souheil, A., Dellagi, S. and Rezg, N. (2012), "Joint optimisation of maintenance and production policies considering random demand and variable production rate", International Journal of Production Research, Vol. 50 No. 23, pp. 6870-6885.

Spillar, R.J. (1997), Park-and-Ride Planning and Design Guidelines, Parsons Brinckerhoff.

Sun, L., Jin, J., Lee, D., Axhausen, K.W. and Erath, A. (2014), "Demand-driven timetable design for metro services", Transportation Research: Part C, Vol. 46, pp. 284-299.

Sun, Y., Guo, Q., Schonfeld, P. and Li, Z. (2017), "Evolution of public transit modes in a commuter corridor", Transportation Research: Part C, Vol. 75 pp. 84-102.

Taha, H.A. (2011), Operations Research: An Introduction, Pearson Prentice Hall,p. 827.

Težak, S., Sever, D. and Lep, M. (2016), "Increasing the capacities of cable cars for use in public transport", Journal of Public Transportation, Vol. 19 No. 1, pp. 1-16.

Trujillo, A. (2013), "Impacto esperado en indicadores de desempeño con la implementación del SPD-Cable en la Línea J del Metro de Medellín”, mater thesis, Universidad EAFIT, p. 261.

Umamaheswari, E., Ganesan, S., Abirami, M. and Subramanian, S. (2018), "Reliability/risk centered cost effective preventive maintenance planning of generating units", International Journal of Quality \& Reliability Management, Vol. 35 No. 9, pp. 2052-2079.

Wang, H. (2002), "A survey of maintenance policies of deteriorating systems", European Journal of Operational Research, Vol. 139 No. 3, pp. 469-489.

Wang, Y., Tang, T., Ning, B., van den Boomb, T.J.J. and de Schutterb, B. (2015), "Passenger-demandsoriented train scheduling for an urban rail transit network", Transportation Research: Part C, Vol. 60 , pp. 1-23.

Wang, Y., Guo, J., Ceder, A., Currie, G., Dong, W. and Yuan, H. (2014), "Waiting for public transport services: queueing analysis with balking and reneging behaviors of impatient passengers", Transportation Research: Part B, Vol. 63, pp. 53-76.

Wu, P.P.-Y. and Mengersen, K. (2014), "A hybrid queue-based Bayesian network framework for passenger facilitation modelling”, Transportation Research: Part C, Vol. 46. pp. 247-260.

Yin, J., Yang, L., Tang, T., Gao, Z. and Ran, B. (2017), "Dynamic passenger demand oriented metro train scheduling with energy-efficiency and waiting time minimization: mixed-integer linear programming approaches”, Transportation Research: Part B, Vol. 97 pp. 182-213. 
General features

Length of the plot (m)

Capacity (pax/h)

Height difference (m)

Medium slope ( $\%)$

Maximum slope (\%)

Stations quantity (unit)

Tower quantity (unit)

Energy

Operational parameters

Vehicle (gondola) capacity, $c v$ (pax/veh)

Quantity of vehicles, $q v_{n}$ (unit)

Commercial speed, $s v_{n}(\mathrm{~m} / \mathrm{s})$

Distance between vehicles, $l v_{n}(\mathrm{~m})$

Frequency of vehicles, $f v_{n}(\mathrm{~s})$

Quantity of stations (unit)

Quantity of platforms, $i$ (unit)

Discretized time, $n$

Travel between platforms (start-end)

Inter-platform length (m)

Inter-platform vehicles (veh)

Inter-platform travel time (s)

Service policy parameters

Travel between platforms (start-end)

Users arrival to platform (Poisson distribution), $\lambda_{i, n}(\operatorname{pax} / \Delta t)$

Effected services average, $\sigma_{i, n}(\mathrm{pax} / \Delta t)$ (uniform distribution)

Maintenance policy parameters

Cost of preventive maintenance action, $C p(\mathrm{mu})$

Cost of corrective maintenance action, $C c(\mathrm{mu})$

Age reduction coefficient (major maintenance), $\alpha_{1}(-)$

Age reduction coefficient (minor maintenance), $\alpha_{2}(-)$

Quantity of minor maintenance per major maintenance, $p(-)$

Stochastic index due the quality of maintenance, $\beta(-)$ (uniform distribution)

2,072
3,000
399
20
49
4
20

Electric (central energetic source) and solar (lighting inside the vehicle)

\begin{tabular}{cccc}
\multicolumn{4}{c}{10} \\
50 \\
5.00 \\
61.67 \\
12.33 \\
\multicolumn{4}{c}{$1,2,3$} \\
\multicolumn{4}{c}{$1,2,3,4$} \\
\multicolumn{4}{c}{$1,2, \ldots, 500$} \\
$1-2$ & $2-3$ & $3-4$ & $4-1$ \\
750 & 900 & 900 & 750 \\
14 & 16 & 16 & 14 \\
170 & 200 & 200 & 170 \\
& & & \\
& & \\
$1-2$ & $2-3$ & $3-4$ & $4-1$ \\
9.0 & 3.0 & 8.0 & 5.0 \\
- & - & - & -
\end{tabular}

Table AI.

Parameters of the transport ropeway system 
Figure A1.

Mean waiting time in the queue, $W g_{i, n}(\Delta t)$
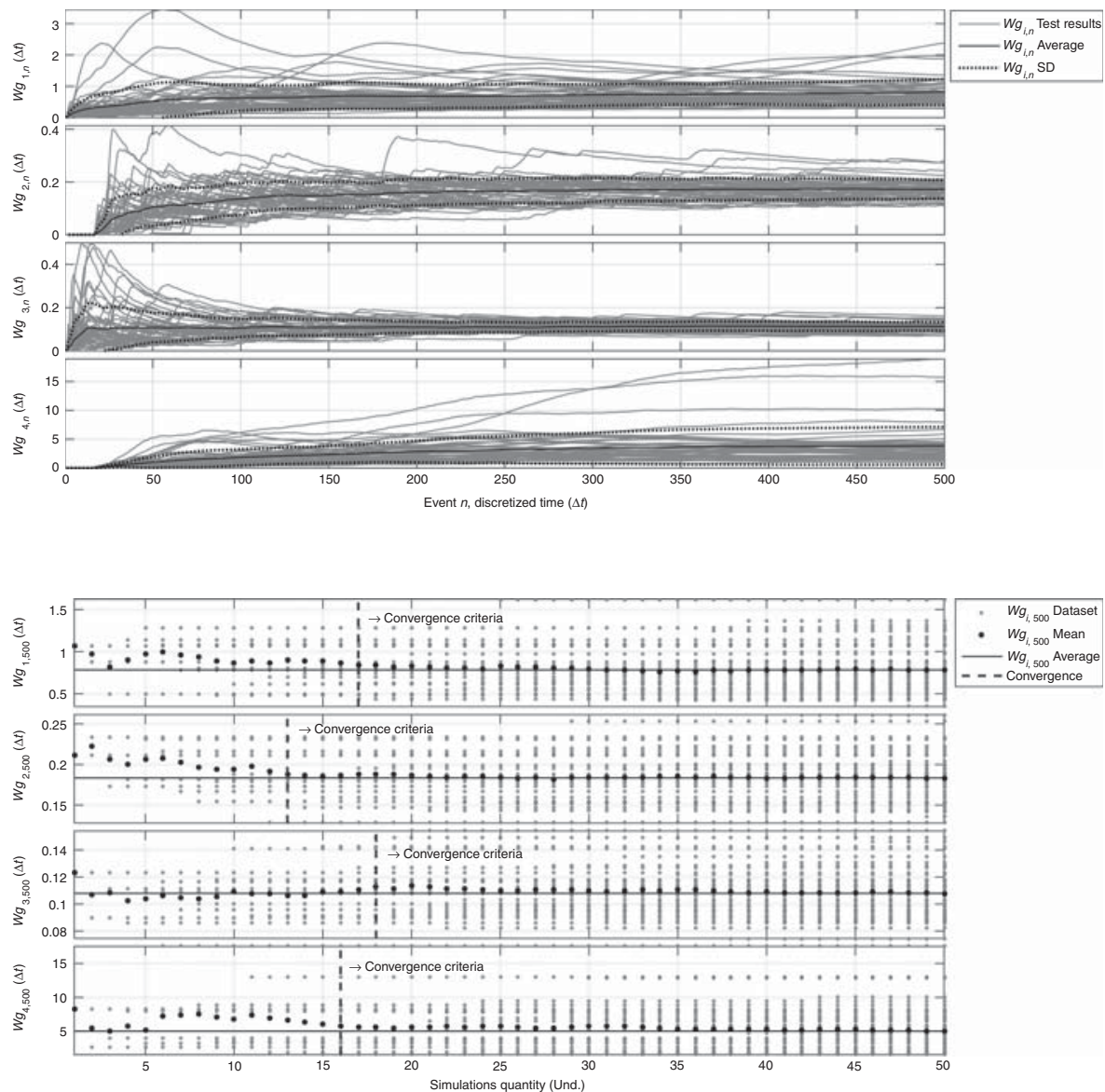

Figure A2.

Convergence analysis result of the numerical model

\section{About the authors}

Ronald Matricie Martinod is Associate Lecturer at EAFIT University (Colombia) since 2015. His research experience has been gained working at research projects which provide support to organisations in the design, development and improvement of products, services and technical processes, with emphasis on management and operation of industrial maintenance, supported on national and international standards and methodologies. His major research fields are dynamic modelling of railways and ropeways, including nonlinear analysis of vehicles. Ronald Mauricie Martinod is the corresponding author and-can be contacted at: rmartino@eafit.edu.co

Olivier Bistorin is Associate Professor at ICN Business School since 2012. He exercises his research activities within the laboratory LGIPM in Metz. After the obtaining of an engineer title in mechanics and production at the ENIM, he presents his doctorate to the University Paul Verlaine - Metz in 2007, entitled "Methods and tools for helping the design of operational processes of skills production systems". Contractual professor in the ENIM until September, 2010, he becomes a research engineer at the university of Lorraine until September, 2012. His main research interests concern the development of methods and tools for the design and the piloting within the framework of the goods and services 
production systems. Indeed, his works concerned industrial companies but also learning systems and healthcare systems. His teaching domains concern the production management, the industrial logistics, information systems and the systems engineering. He is the author of numerous international communications in the community of the industrial engineering,

Leonel Castañeda received PhD Degree from the University of Technology and Life Sciences in Bydgoszcz (Poland) and MS Degree from the University of Science and Technology of Krakow (Poland). He is Professor of the Mechanical Engineering Department and coordinator of the Research Group of Industrial Maintenance (GEMI) technical diagnosis line. His research interests include topics related to mechanic vibration and technical diagnosis,

Nidhal Rezg is Doctor of Industrial Automatic at the National Institute of Applied Sciences (INSA) in Lyon in 1996. He obtained his Accreditation to supervise research (HDR) from the University of Metz in 2003. He was Professor at the Faculty of Engineering of the University of Moncton, New Brunswick, Canada, from 1997 to 1999 and Associate Professor at the University of Metz until 2004. He currently holds the position of Professor of University. He has been Director of LGIPM laboratory since October 2006 and was scientific responsible of the INRIA CosTeam team from 2007 to 2011. His research interests are the optimisation of maintenance policies coupled to production, the optimal control SED. He is the author of 60 papers in international journals, director of 12 theses and 4 accreditations to supervise research

For instructions on how to order reprints of this article, please visit our website: 